\title{
The development of problems within the phlogiston theories, 1766-1791
}

\author{
Geoffrey Blumenthal ${ }^{1} \cdot$ James Ladyman $^{1}$
}

Published online: 2 August 2017

(C) The Author(s) 2017. This article is an open access publication

\begin{abstract}
This is the first of a pair of papers. It focuses on the development of the most notable phlogistic theories during the period 1766-1791, including the main experiments that their proponents proposed them to interpret. There was a rapid proliferation of late phlogistic theories, particularly from 1784, and the accounts of composition and important implications of the main theories are set out and their issues analysed. Each of them either reached impasses due to internal problems, or included features that made them unacceptable even to other phlogistians. The expositions and analyses of these theories are given in terms of details that were in the literature at the time or otherwise potentially understandable by the participants given contemporary practice. Some relevant methodological aspects of the history of science are discussed, and the secondary literature is briefly surveyed. The second paper deals with the contemporary development of the new chemistry, and with theory comparison and theory choice in the same period.
\end{abstract}

Keywords Phlogiston - Lavoisier · Priestley · Cavendish · Kirwan · Scheele · Macquer · Gren

\section{Introduction}

This is the first of two papers. It deals with the development of problems in the main later phlogistic theories between 1766, when Cavendish published his three papers on airs and 1791, when Kirwan abandoned phlogiston, while the second deals with the contemporary development of the new chemistry, and with theory comparison and theory choice in the same period.

In the vast historiography on the chemistry of the period 1766-1791, there are various problems with how the phlogiston theories are represented. Although Partington (1962,

Geoffrey Blumenthal

gb0859@bristol.ac.uk

1 Department of Philosophy, University of Bristol, Cotham House, Cotham Hill, Bristol BS6 6JL, UK 
p. 605) showed that "from about 1770 the latest developments of the theory agree only in their difference from the opinions of Stahl", much of the secondary literature has continued to refer to "the phlogiston theory", without clarifying what is meant by this phrase. The classic study of the late phlogistic theories by Partington and McKie (1937-1939) was mainly focused on the nature of phlogiston itself and on the issue of weight gain in calcination. The current paper focuses on wider issues of chemical composition and details the differences between the late phlogistic theories. Among other matters, this gives further clarification of why it is difficult to produce accurate statements about any pair or collection of them.

This paper analyses the compositional features, implications and problems of each of the main late phlogistic theories. The expositions and analyses are not 'presentist' or 'Whiggish' in that they are in terms of details that were in the literature at the time or otherwise potentially understandable by the participants given contemporary practices. At the cusp of the period, Macquer's (1764) textbook showed that while chemistry had made major advances in experimental knowledge, the primary chemical elements were still stated as earth, air, water and fire as in Empedokles. During the period, the main revised phlogistic theories either reached specific impasses, or included features which made them unacceptable even to other phlogistians. In particular, Cavendish's (1784a, 1785) and Priestley's ${ }^{1}$ theories included numerous internal inconsistencies.

In order to contextualise the late phlogistic theories, it is firstly necessary to review the main features of Stahl's theory and the most notable phlogistic theories after Stahl but before 1766. It is also necessary to consider Priestley's theories from 1793 to 1794 . In these two ways, the paper looks beyond its general period limit. Many issues that are briefly mentioned in this paper potentially deserve more detailed treatments. Comparisons between the phlogistic theories, as well as comparisons with the new chemistry, are given in the second paper. There was an aftermath that lasted until 1813, and this will be discussed in a subsequent paper. It is not possible to deal in the present papers with the many interesting philosophical implications of the story though some are discussed in the second paper. There are also many social and contextual issues that are relevant, but outside the scope of what follows.

The first section is "Phlogiston and related problems before 1766". Section "Phlogistic theories and their problems, 1766-1781" looks at the development of practices and theories and the problems with phlogistic theories from 1766 to 1781 . The third section is "Phlogistic theories and their problems, 1781-1791". Section "Brief notes on implications for the methodologies of the history of science" summarises some relevant implications. The last section gives "A brief survey of selected themes in the secondary literature".

\section{Phlogiston and related problems before 1766}

By 1766 , the theory of phlogiston had become the most influential in chemistry. As a noun the word "phlogiston" was first used by Stahl and it was originally part of a wider view, which built on the previous work of Becher in collecting together ideas from previous

1 Priestley (1772a, 1774, 1775a, 1777, 1779, 1783, 1786, 1788a, b, 1789, 1790a-c, 1791). Some comparisons will also be made with Priestley $(1793,1794,1800)$. 
writers, and which covered an exceptional range of general as well as detailed points in chemistry. Stahl's own style is difficult to read and his views varied, so the scope and attempted comprehensiveness of his work is arguably more evident in Juncker's relatively readable, coherent and detailed presentation. ${ }^{2}$ Juncker (1757, p. 65) stated that "one sees how much order within ideas is necessary in this study [chemistry] and how vain are those who... wish to assert their method as the most recent, the most philosophical and the most interesting, whereas in truth they only give an undigested tissue of experiments without order". Nevertheless, by 1766 there was no consensus concerning many of Stahl's ideas. Only a small proportion of them were adopted in the most influential chemistry textbook of the time (Macquer e.g. 1764), and of these, the dominant idea was that of phlogiston.

Phlogiston was a "principle" in Stahl's version of a type of theory in which the matter that is perceived by humans was hypothesised to be composed of, and/or influenced by, smaller entities of which there were a small number of general types. Prior to Stahl it had become usual for each writer on chemistry to adopt some set of these elements or principles. ${ }^{3}$ Becher's mature theory involved four principles, which were adopted by Stahl, and these were water and the vitrifiable, inflammable and mercurial earths (Juncker 1757, p. 113).

There was a standard problem with such views of the basic elements or principles, which was evident in the French chemistry textbooks from the seventeenth century. It was proposed that chemistry dealt with the decomposition and recomposition of substances, but it was not possible to decompose substances into the proposed principles in practice. In Stahl's version, "distant causes are almost always unknown, so chemistry looks at proximate causes" (Juncker 1757, p. 11), but in stating how entities were constituted in terms of his principles he was not looking at proximate causes. Stahl attempted to justify his version of the primary principles with the a priori statement that the number of primary bodies must "of necessity be very few" (c.f. Juncker 1757, p. 131), but he did note that his "hypothesis... of four principles is not strictly true" (Stahl 1730, p. 10). In the attempt to support this feature of the theory, Juncker $(1757$, p. 151) claimed that "it is a popular error to give the title of principle to the substances produced by analysis", and (1757, p. 132) argued that "the system which gives a particular and immutable form to each sort of thing, in order to establish an astonishing number of primordial entities" was an "ingenious frivolity". In Stahl's view, "we can only demonstrate the principles by transposing them from one combination to another" (Juncker 1757, p. 151). Yet while it could be inferred that something was transferred between different combinations, the available evidence actually did not determine that this was phlogiston or another of Stahl's principles, rather than some other substance that caused or accompanied the same perceptible effects.

Prior to Stahl, many different theories had been proposed as to how the elements or principles linked to putative contents of apparently empty space, and to theories of the natures of heat, combustion, fire and light. For Stahl, phlogiston is found, not only combined in substances, but throughout the universe (Juncker 1757, p. 255). In Stahl's (1697, p. 84) theory, heat is the motion of molecules, while phlogiston is a material principle; changes of state are not due to heat, and phlogiston is not heat. According to Stahl, there is

\footnotetext{
${ }^{2}$ For example, Lavoisier possessed the 1757 French translation of Juncker's work as well as the 1730 original, Beretta (1995, p. 171), and the following Juncker quote appears to be the clear source for Lavoisier's (1774, p. 512) comment that Priestley's (1772) paper was a tissue of experiments hardly interrupted by any reasoning.

${ }^{3}$ In the tradition of French books on chemistry, De Clave (1641) thought that fire was not an element but several phenomena and that air did not enter into compound bodies, so his five elements or principles were water, earth and mercury, sulphur and salt. This list was followed by Lefebvre (1664), Glaser (1677), Lemery $(1677,1720)$ and Homberg (1702).
} 
a difference between the hypothesised primary principles and their mixts and compounds concerning change of state. Each of the four principles including phlogiston is the same in all realms despite change of state (Juncker 1757, p. 146), but the states of other substances were hypothesised to depend on how they were constituted in terms of the principles. Phlogiston causes the emission of heat and light in fire, and Juncker (1757, p. 135) argued that the purer phlogiston is when mixed with substances, the more it made them volatile and ready to be attracted by air. Stahl knew of the phenomenon of effervescence, which he said phlogiston was incapable of causing, and which he argued was really due to water. "All bodies which are subject to becoming fluid, which can be reduced to vapour, or which are elastic, contain the watery principle" (Juncker 1757, pp. 132-133), while the mercurial earth (Juncker 1757, p. 113) was also elastic. So Stahl's theory had several different causes of volatility and elasticity.

Prior to Stahl, there were also several differing theories of combustion and calcination. In Stahl's version, phlogiston is expelled during combustion and during calcination of metals. Nevertheless it had long before been identified that at least some substances increased in weight on calcination. One option for explaining this utilised the Aristotelian view that while earth tended downwards, fire tended upwards, and made substances in which it was contained less heavy; this view was now effectively contrary to Newton's theory of gravity, but was still held by some participants in chemistry. The other generic option for explaining the problem had been that something was absorbed in calcination. Stahl knew of Boyle's theory that the gain in weight of calces is due to the assimilation of igneous particles by the calx, which were able to pass through glass. Stahl may not have known the work on the involvement of air in combustion and calcination by such writers as Rey (1630), and Mayow (1674).

Stahl (1766, p. 277) noted Boyle's type of solution, which he did not accept. He produced several differing explanations of weight gain in calcination (c.f. Partington 1961, pp. 675-677), one of which is that a calx is denser and therefore heavier (Juncker 1757, p. 185), although Boyle had known that calces are less dense than metals. Following Boyle, Stahl knew that without air, combustion did not take place (Juncker 1757, p. 261), and that in a closed space, a certain quantity of air could only support a certain amount of combustion, while no metal would calcine entirely in small closed vessels (Juncker 1757, v. 2, p. 532). He continued an existing type of explanation by proposing that air would take only a certain amount of phlogiston before becoming saturated with it (Juncker 1757, p. 261). Something needed to act to remove phlogiston from the atmosphere, and he thought that plants did this (Stahl and Halle 1718, p. 85). Yet he thought that air did not combine with other substances, and it did not figure among his principles (Juncker 1757, p. 157). The attention and prestige that was accorded to Stahl's theory was one reason why the work on the direct involvement of air in combustion and calcination by such authors as Rey, Hooke and Mayow fell into obscurity.

Because phlogiston was Stahl's version of the previous element of fire and the principle of sulphur, it came with a legacy of varying and additional properties. While phlogiston was hypothesised to stir up heat and to produce inflammability, malleability and ductility, it was also hypothesised to be the cause of colour, odour and flavour (Sennert 1619, 283; Juncker 1757, pp. 127 and 134-135). Stahl changed his mind on colour at a late stage, arguing that colour was not due to a principle present in bodies but due to the reflections and refractions of light, but Juncker (1757, pp. 128, 138-141) argued that phlogiston was the substance and matter of colour, since bodies "are nuanced differently in proportion to the quantity of this principle", and "the manner by which colours are reflected by light is not at all dependent on the manner of being a coloured body". Juncker (1757, p. 167) 
stated that "very obscure ideas" had been held about the principle that Stahl named phlogiston, and it had been described as "earthy, aqueous, or elastic in nature, or as a fatty substance, or a sulphurous, inflammable, oily, unctuous, viscous, etc., matter". According to Stahl phlogiston was a constituent of sulphur, bitumens, asphalte, oils, all parts of vegetables and animals, charcoal, nitric acid, vinegar, tartar, volatile alkalis, metals, and all substances coloured or opaque (Juncker 1757, p. 135).

Stahl argued that there was some experimental evidence that demonstrated the existence of phlogiston. For example, he (1766, p. 93) described that when tin was melted, it became covered with an ash on the surface, but if a little oil, pitch, vegetable resin, tallow or animal fat were thrown on it and stirred, the ash once again became tin. So in this case, he argued that the added materials supplied phlogiston to the ash, or calx, to re-form the metals. The most celebrated of these experiments involved mixing vitriolic acid with charcoal powder (Stahl et al. 1697, p. 118). Juncker (1757, p. 137) argued that vitriolic acid on its own or joined to a fixed alkali was not inflammable, but as soon as one mixed the liquid acid with charcoal powder it made true sulphur that was more inflammable than charcoal itself. He argued that it was "evident" that the inflammable matter had been taken from the charcoal, that it had this property before being taken and conserved it afterwards, that one could add it or take it away from bodies at will, and that therefore phlogiston was a real material. In the context of the chemical knowledge of the time this was one rational interpretation, although among other issues it depended on the assumption that inflammability inhered in a particular kind of substance.

Stahl thought that vitriolic acid was the universal acid (Juncker 1757, v. 5, p. 62). Nitric acid was a compound of vitriolic acid with phlogiston (Juncker 1757, v. 5, p. 181), but sulphur was also a compound of vitriolic acid with phlogiston. The marine acid was a compound of vitriolic acid with the mercurial earth (Juncker 1757, v. 5, p. 237), or the nitric and marine acids were the same (Stahl 1723, p. 357). Stahl considered that phosphorus was a compound of the marine acid and phlogiston (Juncker 1757, v. 4, p. 377) and that phosphorus was a kind of sulphur except that its acid was more subtle. Stahl knew that a "volatile spirit of sulphur" could be obtained, and (1723, p. 297) considered that this was produced by phlogistication and was different from vitriolic acid, in that phlogistication weakens the strength of an acid. This produced an issue with his view that the nitric and marine acids were the same.

In overall terms, Stahl was highly influential on later participants in chemistry, partly because his attempted comprehensive view of chemistry introduced a certain amount of order among a profusion of chemical facts. His concept of phlogiston was very widely accepted, partly because it derived from the long-standing idea that the combustibility of a substance was due to its content of the principle of combustibility, and partly because it appeared to receive some confirmation by four empirically observable matters: firstly, combustion and calcination had something in common; secondly, combustion involved the release of light and heat ${ }^{4}$; thirdly, reduction of calces into metals generally required combustion with the addition of charcoal, and fourthly, in some of these cases it appeared to be clear that a substance was transferred, and that the reaction was reversible.

In this context it was not yet crucial that while Stahl had produced the basis of a system in chemistry, in several matters it was not consistent, in others it did not take into account

\footnotetext{
${ }^{4}$ One of many problems with the theory was that the calcination of metals, which involved the escape of phlogiston, was not accompanied by the release of light, while the release of heat was slow and was not readily discernible.
} 
available evidence, and parts of the theory were not testable. In effect, Stahl's theories inherited and did not solve most of the problems which would later lead to work on all phlogiston theories being discontinued. The existence and attributes of phlogiston could not at that time be confirmed or disconfirmed by direct experiment. The proposed compositions of proposed compounds were either underdetermined or unsupported by experimental evidence. The theory had several differing explanations for volatility. There were different mechanisms for change of state for the principles and for other substances. In the theory, air did not react with and was not absorbed into other substances, and this did not fully take into account existing knowledge on the necessary involvement of air in combustion. The theory did not solve the problem posed by the long tradition of knowledge on weight gain in calcination. The theory proposed that a calx could only be reduced in the presence of a body that could communicate to it the necessary phlogiston, although it was known that mercury calces could be revived without addition.

Macquer's (e.g. 1764) textbook demonstrates the extent to which Stahl's theory was then deemed to be teachable. This work followed the French tradition, in which chemistry textbooks usually had a small section on the proposed ultimate substances, while concentrating mainly on operations on experimentally-available substances, and without proposing detailed links between the proposed overall theory and the practical operations. ${ }^{5}$ Macquer greatly admired Stahl, but did not adopt most of the main points of Stahl's attempt at a comprehensive view of chemistry, including Stahl's four principles. Macquer (1764, pp. 3-9) followed Rouelle in returning to the view that the most basic elements or principles were earth, air, water and fire. Although Macquer was firmly committed to the concept of phlogiston, he (1764, p. 10) thought that it was not a basic principle but a compound. He (1766) adopted the view that heat was a material substance, contrary to Stahl's view that it was the motion of particles. Macquer $(1766$, v. 1, p. 258; 1778, v. 1, p. 345) thought that perhaps all metals could be calcined to a point at which they were all the same type of earth. However he agreed with Stahl that phlogiston was a constituent of metals, sulphur, phosphorus and carbon. He also followed nearly all of Stahl's views on acids such as $(1764$, p. 23$)$ that there was a "universal acid" which was oil of vitriol, as well as the view $(1764$, p. 34$)$ that phosphorus was a kind of sulphur which consisted of the marine acid plus phlogiston.

An attempt was made to deal with the problem of weight gain by calces, given the theory that calcination only involved the removal of phlogiston from metals. In 1764, Chardenon applied to phlogiston a version of the long-standing view that the matter of fire was characterised by an inherent lightness or levity, ${ }^{6}$ but this was criticised on the grounds that " $\mathrm{M}$. Chardenon should have arrayed against him all the astronomers and all the physicists who believe in universal gravitation". 7 This showed that if the weight-gain problem was explicitly faced, it became evident that it was at least extremely difficult if not impossible to solve.

In sum, Stahl's theory of phlogiston was very widely accepted in view of its apparent empirical successes, and because there was no adequate rival theory. In this context it was not crucial that it had several basic inherent problems, or that there were now several versions of the theory with different and competing hypotheses on specific matters, or that many matters in Stahl's attempted comprehensive view had been shelved. The number of

\footnotetext{
${ }^{5}$ In particular, Macquer partly followed and partly differed from the unpublished work of Rouelle, who had introduced a modified version of Stahl's views in his teaching, c.f. Rappaport (1961).

6 An abstract was published in Chardenon (1765), and the full memoir in Chardenon (1769). C.f. Partington and McKie (1937, pp. 373-379).

7 'Ribapotme' (1768), Chardenon (1768) replied intemperately.
} 
items that a phlogistic theory or a competing theory needed to be able to explain, in order to be competitive, was already large.

\section{Phlogistic theories and their problems, 1766-1781}

\section{Cavendish and Guyton, 1766-1772}

The discovery and identification of different types of air, and the attempts to explain these within the phlogiston theory, began a rapid increase in the number of details that any theory of chemical composition needed to explain, and a consequent increase in the difficulties faced by phlogiston theories. All these matters can be seen in Cavendish's (1766) set of papers.

Cavendish's work followed up on the work of Black on "fixed air", and on the work of Boyle on the inflammable "fume". Cavendish undertook a thorough research programme on collecting and analysing these and other types of air, and his papers mainly report his copious and admirable experimental findings and his empirical interpretations of them. He found that when some metals were dissolved in dilute vitriolic acid, an "inflammable air" was produced, ${ }^{8}$ which appeared to be at least nearly the same type of air in each case, and which could not burn without the assistance of common air. He (1766, pp. 150-153) measured the specific gravity of "inflammable air", compared with that of common air and that of water and, depending on information from experiments by others, found that it was between 7 and 11 times lighter than common air, or between 5490 and 9200 times lighter than water. In contrast, when some metals were heated in undiluted sulphuric acid, volatile sulphureous fumes were formed which were not inflammable, and when these metals were dissolved in nitrous acid, a nitrous air was formed. All this advanced chemistry and added crucial matters to those that any wide theory needed to explain.

Cavendish's theoretical interpretations of these experiments relied partly on Stahl's concept of phlogiston and partly on Boyle's work on the inflammable fume. Boyle (1672) had described this as consisting of "the volatile sulphur of Mars, or of metallic streams participating of a sulphurous nature", and he recognised it as a substance. ${ }^{9}$ Boyle did not connect this substance with his theory of calcination, in which the gain in weight of calces is due to the assimilation of igneous particles by the calx.

Cavendish's phlogistic interpretations also departed from the rigorously empirical style of most of the material in his papers, in that they were effectively applied after the experiments, and he did not test them even though in some respects they were testable. Concerning his inflammable air, Cavendish's (1766, p. 145) interpretation was that when the metals he had used were dissolved in spirit of salt or dilute vitriolic acid, "their phlogiston flies off, without having its nature changed by the acid, and forms the inflammable air". ${ }^{10}$ Cavendish then took into account the existing phlogistic theory that

\footnotetext{
8 Light "inflammable air", which is now known as hydrogen.

9 Boyle 1680 - "But because the most intelligible and least indefinite notion their writings suggest of sulphur is that "tis a combustible and inflammable principle, I have hitherto treated it as such".

${ }^{10}$ Many writers have assumed that Cavendish's statement that phlogiston "forms" inflammable air indicated that it was inflammable air. It has also been argued that his statement is potentially ambiguous, e.g. by Sudduth (1978, p. 145). In the context of his other interpretation that in the case of undiluted acid the phlogiston had its nature changed by the acid, if he did not mean that in the case of diluted acid the phlogiston was the inflammable air, he presumably implied that the phlogiston, in forming the inflammable air, might have united to an unknown substance which did not change its properties.
} 
sulphur consisted of vitriolic acid united to phlogiston. He (1766, pp. 145-146) inferred that when he heated and dissolved metals in undiluted vitriolic acid, the phlogiston that was given off from the metal united to the acid to form his sulphureous air, losing its inflammable property in so doing, while the smell of the resulting air was due to the phlogiston which it contained. He then followed Stahl (1723, p. 297) in inferring that "the volatile sulphureous acid appears to consist of the vitriolic acid united to a less proportion of phlogiston than what is required to form sulphur". In a similar manner when metals were dissolved in nitrous acid, Cavendish inferred that their phlogiston united with part of the acid to form the nitrous fumes. In this case he contradicted Stahl's (1723, p. 395) views that the nitric and muriatic acids were the same, and that they consisted of vitriolic acid and the mercurial earth (Juncker 1757, v. 5, p. 237).

Cavendish's views gave the appearance of being an extension, or even a consolidation, of Stahl's views to cover the new experimental evidence. Yet they actually differed in additional ways from Stahl's, they had additional problems, and Cavendish did not test the potentially testable consequences of these theories. Firstly if inflammable air was phlogiston, Cavendish's version of phlogiston was ponderable, but in that case it consolidated the problem with Stahl's theory which entailed that metals should weigh more than or the same as calces, whereas there was already much experimental evidence which showed that calces were heavier than metals. Secondly, in Stahl's theory, air that was saturated with phlogiston suppressed combustion (Juncker 1757, p. 261), but in Cavendish's theory phlogiston formed highly inflammable air. Thirdly, if inflammable air was phlogiston it should have been present in all of the substances in which phlogiston was supposed to be present, but he did not test this. Fourthly, because charcoal was Stahl's main example of a substance that was nearly all phlogiston, inflammable air should have acted as a reducing agent in largely the same fashion that charcoal did, or some auxiliary hypothesis would have been necessary to explain why this was not the case. Fifthly, in all the cases that the combination of phlogiston with one substance was hypothesised to form another substance, it was experimentally possible to put inflammable air together with the first substance and test what was formed in the reaction. For example, while Stahl had put vitriolic acid and powdered charcoal together and formed sulphur, which was hypothesised to have been due to the union of the phlogiston from the charcoal with the vitriolic acid, if Cavendish identified phlogiston with inflammable air, the combination of vitriolic acid and inflammable air should have formed sulphur, but he did not report any such tests. Sixthly, in the same sorts of reactions, the end product should have been heavier than the initial substance by a weight equalling that of the inflammable air that was used and that disappeared in the reaction. For example, vitriolic acid plus inflammable air should have formed sulphur that was as heavy as the initial substances, but he did not report such tests. Seventhly, Cavendish's theory resembled Macquer's in that he had taken views from differing sources and in effect had created a revised phlogistic theory which had internal problems and which was not systematic in the sense that Stahl's had been.

By far the most important point about Cavendish's paper is that it involved very significant advances in experimental chemistry on types of air. The preceding argument does not imply that his phlogistic interpretations were central to his paper-he may well have thought of them as incidental to his primary experimental work. Yet his interpretations added to the potential problems that were accumulating concerning the presence of phlogiston in substances and concerning phlogiston and weight.

Following on from Chardenon's work and the associated controversies, Guyton (1772) was the first to show clearly that weight gain during calcination was a general phenomenon, and this achievement was praised on 8 February 1772 by Macquer when he read 
a digest of Guyton's paper to a session of the Académie. ${ }^{11}$ Guyton produced the revised proposal that the addition of phlogiston to a metallic calx made the metal lighter, because it was specifically lighter than air, but this explanation was no more workable than Chardenon's and was not adopted. This work was a further indication that the weight issue for phlogistic theories was a crucial anomaly.

To sum up, it was during this period that work on types of air began significantly to add to the experimental evidence that any comprehensive theory of chemical composition would need to explain. Cavendish's theory that phlogiston formed inflammable air, although apparently in line with Stahl's views, created several new potential problems for phlogistic theories. Guyton's investigation of weight gain in calcination confirmed the generality of the problem for the phlogiston theory and did not produce a satisfactory answer.

\section{Priestley, 1769-1779}

The types of differences between generally empirical work and work with phlogistic interpretations, which had occurred in Cavendish's seminal paper, also occurred among Priestley's earliest published scientific works. ${ }^{12}$

Priestley's (1772a) first major paper on air added so significantly to Black's and Cavendish's work on fixed air, and to Cavendish's (1766) work on inflammable air and on the type of air resulting from the marine acid, as well as covering other topics concerning air, that it was rightly perceived as a landmark in the development of the chemistry of air. For example, Lavoisier (1774, p. 111) commented that Priestley's (1772a) paper had involved the most work and was the most interesting that had appeared since that of Hales on the subject of the fixation and disengagement of airs. Priestley's procedures often involved heating substances or dissolving substances in acids (Browning 1934, pp. 171-172), observing the results, forming heuristic hypotheses and then testing these hypotheses. For example, in his (1772a, pp. 234-238) section on air procured by means of the marine acid, he started from Cavendish's experiment in which he had obtained a remarkable kind of air by putting copper into the acid and applying heat. Priestley performed several experiments that led him to the hypothesis that the air was produced from the spirit of salt alone, which he tested experimentally and confirmed by heating the acid alone.

Priestley's work on inflammable air involved some unusual examples in which a phlogistic hypothesis was tested. Priestley (1772a, p. 178) differed from Cavendish's (1766, p. 145) hypothesis that inflammable air was phlogiston, by hypothesising that inflammable air was air united to or loaded with phlogiston. As already stated, this was opposite to Stahl's theory, according to which, air saturated with phlogiston suppressed combustion (Juncker 1757, p. 261). He then formed the heuristic hypothesis that if inflammable air were exposed to some substances that were said to have a close affinity with phlogiston, it would then become less inflammable. Yet he stated that neither of his tests of this hypothesis "succeeded".

\footnotetext{
11 Macquer (1778, v. 1, pp. 346-347), again praised Guyton for this work.

12 Priestley (1769, p. 544), recommended that the history of a "branch of science" would be "most favourable to the progress of knowledge" if written using what he called the "analytic" method, setting out the historical processes and real views involved, "false and imperfect as they often were", rather than by the "synthetic" method in which a single picture is given and false views are concealed. The analytic and historical method is followed in the current paper.
} 
More usually Priestley's phlogistic hypotheses resembled Cavendish's in that they were based on Stahlian precedents and he did not test them. In the first of three especially noteworthy sets of experiments on calcination or reduction in closed conditions during 1772-1775, Priestley (1772a, pp. 228-229) suspended pieces of lead or tin in given quantities of air and threw the focus of a burning mirror or lens on them, "so as to make them fume copiously". The air was diminished greatly, in his judgement more than in the case of his other experiments on diminution of air. He noted the facts that the quality of the air changed to noxious, that his water changed colour and there was a white deposit over the water and the sides of the phial, but he did not explore the latter two changes in any further detail or attempt to explain what was involved in them. Priestley's interpretation started from the basic Stahlian view that the calcination of metals simply involved the escape of phlogiston. ${ }^{13}$ On the grounds of the apparently greater diminution in the case of calcination, Priestley assumed that in his other experiments there had been "a cause of addition also, either of fixed air or inflammable air ${ }^{14}$ or some other permanently elastic matter", and inferred that there had been no such addition in the case of calcination. He apparently did not consider any other possible hypotheses, but nevertheless argued that this was an experimentum crucis. His orthodox Stahlian conclusion was that "in the experiments with metals, the diminution of air seems to be the consequence of nothing but a saturation with phlogiston" (1774, p. 139). It is striking how different his interpretative process in this case was from his official methodology which involved forming heuristic hypotheses, testing them and interpreting them without using prior general concepts.

Priestley's (1774) first book on types of air included the material from his (1772a) earlier paper, as well as new work on the types of air resulting from the vitriolic and nitrous acids, and on the types of air remaining after processes of the diminution of air. Subsequently Priestley's discoveries were rightly even more widely admired: for example, Fourcroy (1796, p. 379) stated that Priestley's volume contained "a mass of discoveries that was much greater than everything that had been observed before then" on the subject, and became "known throughout Europe within a few months".

This book included the second of Priestley's (1774, p. 193) noteworthy experiments on reduction or calcination in closed conditions. This implicitly reacted to Lavoisier's (1774) identification following a wide variety of experiments that air was always absorbed during calcination, and his (1774, p. 621) indication that Priestley had not noticed this absorption. Priestley reduced red lead, and "expelled from it a quantity of air about four or five times the bulk of the lead, the air being received in a vessel of quicksilver", as well as a small quantity of water. Priestley stated that he then terminated the experiment without waiting to see how much additional air the experiment would produce. Priestley said that it "immediately" occurred to him that "this water and air together must certainly be the cause of the addition of weight in the calx". Admitting water to this air, Priestley found that the air was imbibed by the water, exactly like fixed air, and so Priestley "immediately" concluded that the air was fixed air, and he considered that he had never obtained fixed air so pure (1774, p. 193). ${ }^{15}$ Priestley (1774, pp. 178-179) re-formulated his previous conclusion as being that whenever air was diminished, the common cause was that the air became overcharged with phlogiston, and he argued that his recent experiments had tended to support this conclusion. He (1774, pp. 181-182) now hypothesised that "the manner in

\footnotetext{
${ }^{13}$ Priestley used a "rudimentary" Stahlian concept (McEvoy 1978, p. 99) of a phlogiston which had never yet been demonstrated by itself in any form (Priestley 1774, p. 260).

14 This may be one of the instances in which Priestley was referring to heavy inflammable air, CO.

15 Priestley stated that "how much more air it would have yielded, I did not try".
} 
which air is diminished by being overcharged with phlogiston [is that] the phlogiston [has] a nearer affinity with some of the constituent parts of air than the fixed air which enters into the composition of it, in consequence of which the fixed air is precipitated", and (1774, p. 187) united with "some other substance at hand with which it had an affinity, such as lime-water or the calces of metals".

However, in effect this was no longer Priestley's former orthodox Stahlian theory of calcination. Priestley now knew that calcination and reduction involved the transference of a substance that was not phlogiston, and that this other substance accounted for the diminution of air and for the increase in the weight of the calx. Yet the transference of a substance had been the central evidence that was interpreted as demonstrating the existence of phlogiston (Juncker 1757, p. 151) and the weight problem was the central apparent problem with Stahl's theory. Nevertheless, Priestley went on asserting the standard theory of phlogiston. "Belief in [phlogiston's] existence was unjustifiable on Priestley's epistemic criteria", ${ }^{16}$ but Priestley (1774, p. 282) continued to think that the difference between metals and metallic calces had to be due to the transference and presence of a "real something" which he regarded as corroborating the existence of phlogiston. Accordingly, Priestley had formed a new hybrid type of theory in which phlogiston was still retained as a hypothesis, even though the actual evidence for transference now related to a different substance.

In this book there were several other noteworthy hypotheses, from which other participants differed during the next two decades. For example, he (1772a, p. 162, 1774, p. 43) hypothesised that "it is phlogiston that fixed air wants to turn it into common air", He also hypothesised that air that had been vitiated by respiration could be restored by the removal of its fixed air. He (1772a, p. 173) hypothesised that "inflammable air is convertible into air fit for respiration" and (1772a, p. 239) that "acid air and phlogiston make inflammable air". Priestley considered that the latter reaction also applied in the case of vitriolic acid air, and he $(1774$, p. 263$)$ produced the speculative hypotheses that "it seems not to be improbable, that these two ingredients are the only essential principles of common air" and that "it may not be improbable but that the volcanos... may have been the origin of our atmosphere, as well as... of all the solid land". ${ }^{17}$ His hypotheses differed drastically from Stahl's (1723, p. 297) and Cavendish's (1766, pp. 145-146) concerning the products of vitriolic acid air and phlogiston.

The third of Priestley's highly noteworthy experiments or sets of experiments on calcination or reduction during the period $1772-5$ was his reduction of mercurius calcinatus $^{18}$ in initially airless closed conditions. Priestley focussed the light from a burning glass onto the calx in a glass vial that had then been filled with mercury and inverted in a basin of mercury (Priestley 1775a, pp. xxxv-xlii and 33-34). An air was produced, and the remainder of what had been the initial calx joined and was indistinguishable from the mercury. He then performed further experiments on this air, finding among other matters that it was not imbibed by water, unlike "fixed air". He also extracted a quantity of the same kind of air by reducing red precipitate of mercury ${ }^{19}$ and by reducing red lead (1775a, pp. 35-37). Priestley rightly identified that this was a distinct type of air that had

\footnotetext{
16 McEvoy (1978, p. 111).

17 C.f. Macquer (Macquer 1764, p. 23), who stated that vitriolic acid was widespread in the air as well as in all nature including waters and the bowels of the earth.

18 Now known as mercuric oxide, $\mathrm{HgO}$.

19 This was produced by a different method than mercurius calcinatus, but is now also known as mercuric oxide, $\mathrm{HgO}$.
} 
not been previously recognised as such in a publication. Fourcroy (1796, p. 379) judged that this discovery was "even more important" than those in Priestley's (1774) first volume.

Yet Priestley had previously produced from red lead what he (1774, p. 193) had identified as the purest fixed air he had ever obtained. He (1775a, p. 37) now produced the auxiliary hypothesis that it must require more heat than he had previously used in order to expel the new type of air. Later he (1775a, p. 49) hypothesised that what mattered was the care taken to extract the fixed air from the red lead. An experiment (1775a, pp. 66-67) extracting at different times a series of quantities of air from a sample of white lead, without any addition, showed that the first was predominantly fixed air, and the rest became more pure, while only the last was pure air, free from fixed air. He stated (1775a, p. 217) that fixed air was always contained in common air, that it was always contained in dephlogisticated air, and that when dephlogisticated air was procured by any process whatever, there was always a considerable quantity of fixed air mixed with it. The last three of these points were reasonable, but he did not take them into account in his later work, as will be seen in section "Priestley 1785-1791".

His interpretation of his experiments differed from his 1772-1774 interpretations. While his discovery had had nothing to do with the concept of phlogiston, his interpretation centred on it. Concerning his new air, he hypothesised that "being capable of taking more phlogiston from nitrous air, it therefore originally contained less of this principle" (Priestley 1775 a, p. 48) and he accordingly named the new air as "dephlogisticated air". ${ }^{20}$ However, he did not apply his concept of "dephlogisticated air" to the experiment that he had done to create the air in the first place. If he had done so he would have found a problem, in that there was no 'free air' present within the glass vial from which phlogiston could be absorbed.

So his name for his air was inaccurate for the experiment in which he had produced the air, or he would have needed to add at least one significant qualification to his hypotheses. Stahl had rejected Boyle's idea of the fixation of igneous corpuscles that could penetrate glass, but one option for Priestley would have been to hypothesise that phlogiston passed through glass. ${ }^{21}$ Another option would have been to hypothesise that the calx contained common air, which would have differed more than Priestley already had done from Stahl's theory, by assuming that phlogiston was not emitted but stayed within the calx united to the dephlogisticated air. ${ }^{22}$ Such a conceptual step would have involved partly if not wholly abandoning Stahl's central tenet that it is the presence of phlogiston in metals that gave them their metallicity while its absence gives calces their own natures. Given Stahl's identification of the similarity of the processes of combustion and calcination, this would also have implied that this phlogistic theory would be in tension with Stahl's view that the release of phlogiston was what explained the emission of light and heat in combustion.

\footnotetext{
${ }^{20}$ Priestley (1775b, p. 387) also produced the interpretation that "as I think I have sufficiently proved that the fitness of air for respiration depends on its capacity to receive phlogiston from the lungs, this species may not improperly be called dephlogisticated air". This interpretation has the same problems as the nitrous air interpretation.

21 Priestley did not recognise this possibility in print until his 1800, p. 36, when he quoted Scheele's 1780 adoption of this idea; Scheele (1931).

22 It was nine years later in 1784 that Cavendish (1784a, p. 144), first published a conceptual step of this generic type, although crucially it was not this specific hypothesis.
} 
Priestley also produced speculative hypotheses about the nature of the new air. He noted that red precipitate was produced by a solution of mercury in spirit of nitre, ${ }^{23}$ and he now hypothesised that the peculiar nature of the new air was due to nitrous acid. He then speculated that since mercurius calcinatus was produced by exposing mercury to a certain degree of heat in common air, it must have "collected something of nitre... from the atmosphere" (Priestley 1775a, p. 35). This was an echo of Mayow's (1668, p. 43-44) theory of aerial nitre that Mayow thought was the part of common air which was breathed into the lungs. ${ }^{24}$ Priestley again came to conclusions involving phlogiston without apparently considering any other possibilities and also without considering his previous experiments. He speculated $(1775 b$, p. 392) that "there is a regular gradation from dephlogisticated air, through common air, and phlogisticated air, down to nitrous air; the last species of air containing the most, and the first-mentioned the least possible phlogiston." He stated that "there remained no doubt in my mind... that atmospherical air, or the thing that we breathe, consists of the nitrous acid and earth, ${ }^{25}$ with so much phlogiston as is necessary for elasticity, and likewise so much more as is required to bring it from its state of perfect purity to the mean condition in which we find it" (1775a, p. 55). Although Priestley (1775a, p. 314) protested that he had never said that common air could be changed into fixed air, and that he $(1769$, p. 567) had rather considered fixed air to be an elementary substance, he (1775a, pp. 76 and 316) conjectured that fixed air was a transmutation of the nitrous acid-and given that he (1775a, p. 62) thought that respirable air consists of nitrous acid and earth, this did establish a connection in his thinking between common air and fixed air.

Priestley's views on the constitution of dephlogisticated air changed following further experiments. He (1777, pp. 41-42) argued that the great bulk of dephlogisticated air consists of earth". He (1779, p. 204) argued that dephlogisticated air contains earth and "some acid", and in the same book he (1779, p. 198) suggested that some of his experiments indicated the lack of any acid at all in pure air. More changes will be noted in sections "Priestley and Cavendish, 1781-1783" and "Priestley 1785-1791".

To sum up, Priestley's admirable string of discoveries concerning airs during 1772-1775 was rightly recognised as having significantly advanced chemistry. Yet his discoveries also added to the stock of available experimental evidence that posed very onerous problems of explanation for any phlogistic theory. Although his methodology in chemistry from 1775 until 1786 explicitly favoured the production of "facts" and the avoidance of systematic theorising, his theories during 1774-1775 had increased the likely problems that would need to be dealt with during a future attempt to create a revised phlogistic theory, since such an attempt would need to depart from his views, as will be seen in sections "Priestley and Cavendish, 1781-1783" and "Cavendish 1781-1787".

\footnotetext{
${ }^{23}$ Now known as nitric acid, $\mathrm{HNO}_{3}$.

${ }^{24}$ Interestingly, Schofield (1957, p. 163), clarifies that Priestley is not known to have owned Mayow's 1674 book until after 1792, so it is possible that this idea was suggested to Priestley.

25 The italics are in the original. Prior to this, Priestley (1775a, p. 54), had stated that he had found "that the same kind of air is produced by moistening with the spirit of nitre any kind of earth that is free from phlogiston". This and his result with minium are particularly noteworthy in the light of his later claims that it was only possible to obtain this air from a calx, without the addition of charcoal, in the case of mercurius calcinatus.
} 


\section{Macquer and Guyton, 1774-1781}

Following Lavoisier's (1777b) paper (that is discussed in the second of the present papers), Macquer completed the second edition of his Dictionary, in which (1778, v. 3, pp. 99-144) he included a long article on phlogiston responding to recent developments. He (1778, v. 3 , pp. 126-127) included a substantial quote from Buffon, without naming him, as one focus of an impassioned defence of the concept of phlogiston against any attack.

Macquer argued that even though phlogiston was, of all the principles of matter, the least known (1778, v.3. p. 100), Stahl had set out several general properties of phlogiston, the "truths" of which were "sufficiently illuminated and proven by the details of the phenomena that phlogiston presented in the different experiments of chemistry" (1778, v.3, p. 104), and which had become "very important and essential to know in chemistry" (1778, v.3. p. 121). Macquer argued that "all those who know in detail the phenomena of the operations of chemistry, and who have the genius of that science, that is to say, the faculty of perceiving and comparing the interrelations of these phenomena, are intimately convinced" concerning the nature and qualities of phlogiston. He argued that all the theory of phlogiston, "founded on facts which are as numerous and they are incontestable, has no obscurity for those who know these facts and who understand how to see them" (1778, v.3. p. 122).

Despite all these arguments, Macquer now changed his mind drastically, relative to the statements in his first edition, concerning the natures of heat, of light, of phlogiston and of calcination. Macquer (1778, v. 1, p. 347) admitted that not one of the many hypotheses proposed, up to and including that of Guyton, to account for the gain in weight during calcination, was satisfactory. Macquer now accepted the views of Lavoisier and Bayen that air was absorbed during calcination. Macquer (1778, v. 3, pp. 122 and 132) now went back to Stahl's view that heat was the motion of molecules, and adopted Homberg's (1705) view that the matter of fire was the matter of light. This brought new problems of its own, and subsequently there was a new situation in French chemistry, in that many chemists appreciated his defence of phlogiston but still held his previous view on the matter of fire and heat. Moreover, Macquer did not develop his new views into a detailed systematic theory. Stahl's central proposed evidence for phlogiston had involved the addition of charcoal to substances, and Macquer did not deal with the issue that focussed light had different effects on substances than were obtained by adding or burning with charcoal, so that he had not justified the former phlogiston theory but had created another new phlogistic theory which had substantial difficulties.

Guyton and colleagues (1777-8) now wrote a chemistry textbook in which the current uncertainty about chemical composition was made explicit, to the extent that they found it necessary to argue that chemistry was not a purely speculative science (1777-8, v. 1 , p. 14). Their discussion on simple substances was only five pages long. According to them, water was a natural element that could not practicably be composed or decomposed, and the other natural elements were fire, air and earth, although even these might well actually be compounds and there might well be only one basic substance; there were many other chemical elements which could not be composed or decomposed by chemical means, but which were probably already composed although the art of the chemist could not show this. 


\section{Scheele and Bergman 1775-1781}

Meanwhile, Scheele had been producing a different phlogistic theory; this was published in 1777, and was available in an English translation in 1780 and in a French translation in 1781. Bergman tended to favour Scheele's views although in many detailed cases he did not decide between a variety of views.

One of Scheele's (1931, p. 102) starting points was that "phlogiston is a material substance, which always presupposes some weight". Another was that, due to the facts about latent heat, heat had to be material; Bergman (1784, pp. 341-342) stated that the theory that supposed heat to consist in the motion of bodies is "at present held to be totally improbable". Scheele's work shows awareness of Cavendish's (1766) view that free phlogiston was in the form of inflammable air, of Priestley's (1774, 1775a) volumes and of Lavoisier's (1774) book.

In Scheele's theory, (1931, p. 162) the aerial acid ${ }^{26}$ plus phlogiston probably made "fire air", ${ }^{27}$ which in turn was the basis of all acids. Fire air plus phlogiston made heat, and with more phlogiston it constituted light (1931, pp. 129-131), and with yet more phlogiston it constituted inflammable air (1931, p. 171). Scheele (1931, pp. 103-104) stated that the acid of nitre could be united with phlogiston in different quantities: with just a little phlogiston it became red vapour; with a little more it became an invisible kind of air; and with more it became a kind of air which would not unite with alkalis or with absorbent earths. ${ }^{28}$ Scheele (1931, pp. 171-174) considered that metals are composed of specific earths combined with phlogiston and some heat; the earth is attracted by acids and the phlogiston and heat are expelled as inflammable air. Bergman (1785, p. 234) stated that Scheele's basic hypothesis "is not without its difficulties... it however seems to agree better with experiment than any other", but Bergman thought that "it is highly probable that the metals are only different acids coagulated by a large quantity of phlogiston".

Scheele (1931, p. 97) undertook an experiment on burning hydrogen in air which was confined by water. The air was diminished by one fifth, and no aerial acid was produced. The product of the fire air and inflammable air was not in the water and was missing. Scheele inferred that this product must have escaped through the glass, and consequently that the product was heat which "had gone through the fine pores of the glass and dispersed itself far and wide in the air" (1931, p. 102). Scheele (1931, p. 147) inferred that what happened during the reduction of mercurius calcinatus was that the calx decomposed the heat, combining with the phlogiston to form mercury and setting free the fire air, which was 'pure'.

Leonhardi (1790, v. 6, p. 604) stated that by his time, Scheele's theory that phlogiston combined with fire air to form heat and escape through glass had "lost all approbation". Firstly, given that neither air nor phlogiston could pass through glass, it was not credible that their compound should do so. Secondly, there was no change in weight when combustion occurred in closed vessels.

There were many other potential problems of Scheele's theories, of which the following are some examples. Firstly, the main experimental basis of the theories was due to the burning of inflammable air in common air confined over water. Secondly, it was not clear what substances were simple in these theories and how compounds were built up in these

\footnotetext{
26 Bergman's name for Black's fixed air.

27 Fire air was Scheele's name for dephlogisticated air or pure air or oxygen.

${ }^{28}$ In this, the presence of phlogiston was equivalent to the absence of oxygen. The modern terms are nitrogen dioxide, nitrous anhydride and nitric oxide.
} 
theories. If the constituents of metals other than phlogiston were not simple earths, it was not clear how they were constituted, and other than the aerial acid and phlogiston, it was not clear what the other constituents of acids were. Thirdly, therefore a revised nomenclature with compounds named in terms of simple substances was not practicable with these theories as they stood. Fourthly, if heat caused expansion and contraction, but if heat was ultimately based on the aerial acid, it was unclear why heat functioned in ways in which other substances apparently did not do. Fifthly, it was unclear why fire air was collectable when mercurius calcinatus was reduced, but when combined with phlogiston it suddenly managed to vanish through glass in the form of heat. In addition, some of the problems which have been listed for Cavendish's (1766) theory also applied in this case. Scheele's interpretation of the experiment on burning inflammable air in common air over water was very soon shown to be inaccurate.

\section{Theories on phlogiston and electricity 1766-1781}

In 1767, Priestley wrote to Canton that his electrical experiments made him "inclined to think that there is no electrical fluid at all and that electrification is only some [new] modification of the matter of which any body consisted before that operation" (in Schofield 1966, p. 58). By contrast, in his (1770) paper on the conducting properties of charcoal, he adopted Macquer's (1764, p. 102) view that charcoal was phlogiston mixed with an earth, and interpreted (1770, p. 218) that the conducting power of charcoal was connected to its phlogiston. ${ }^{29}$ This was even though Macquer (1764, p. 102) had stated that water had no affinity for phlogiston, while Priestley knew that water was a conductor (1770, p. 221). As was the case with Priestley's work on airs during this period, his interpretations involving phlogiston and electricity differed from his generally empirical methodology by adopting the concept of phlogiston. He (1774, p. 193) argued that the "revivification of metals by electricity completes the proof of the electric matter being, or containing, phlogiston". He (1774, p. 275) also advanced what he stated were "speculations" connecting phlogiston with electricity "however chimerical soever they may be thought to be". Yet Priestley did not discuss such a connection again during this period.

Independently, De Milly (1774, pp. 146, 148) also used the standard Stahlian view that metals contained phlogiston when arguing for the close analogy of phlogiston with electricity. The latter view was contested by Brisson and Cadet (1775), and was not in favour within the Académie Royale. Cavallo (1777, pp. 112-113) accepted a standard view of phlogiston, but argued that electricity was not similar to phlogiston: if they were similar, they would be found together which was not the case: phlogiston was argued to be present in all substances, but the electrical fluid was limited to conductors; and electricity was propagated through conductors almost instantaneously but fire propagated slowly. Nevertheless Cavallo and Henly (1777) thought that it was probable that phlogiston, the electric fluid and fire were different modifications of the same element. Weber (1778, p. 68) argued that phlogiston was a compound of electrical matter and earth.

In 1781, Sigaud de la Fond undertook as experiment involving a glass tube in which common air was underlain by a a solution of tournesol, and in which an explosion was made by electricity. The explosion caused the air in the tube to diminish, and the tournesol to turn red, indicting acidity. De la Fond did not take into account what was happening to

${ }^{29}$ The first link between phlogiston and electricity had been proposed in 1758 by Beccaria who hypothesised (1776, p. 304) that electrical discharges drove phlogiston off from metals, and (1776, p. 301) that they could also revive metallic calces. 
his air, but (1781, p. 618) interpreted that the result was due to electricity acting in the manner of acids. It is particularly interesting to compare this to Cavendish's outstanding series of experiments at this date and for the next four years (1784a, 1785), which involved electrical discharges and types of air, for which he produced phlogistic explanations which did not link electricity with phlogiston, as will be seen in section "Cavendish 1781-1787".

In sum, it was rational to consider what relationship there might be between the widelyaccepted concept of phlogiston and the developing experimental knowledge concerning electricity. Yet the latter was scanty and the former was at least very difficult to test, so a link between the two concepts was effectively speculative. Such a link was not supported by nearly all the main phlogistians in France and Britain during this period.

\section{Phlogistic theories and their problems, 1781-1791}

\section{Priestley and Cavendish, 1781-1783}

Cavendish (1784a, p. 126) stated that following Priestley's report of an experiment by Warltire, in 1781 Cavendish did some experiments involving the combination of inflammable air and dephlogisticated air over mercury, showing that water was produced with no loss of weight. He did not immediately publish these, partly because at first he had not worked out why there was a small amount of nitrous acid present. He (1784a, p. 134) stated that he told Priestley about these experiments.

Priestley (1783) now published a paper relating to set of experiments involving the reduction of calces in inflammable air, which he performed over a water trough. In this case, he did not take into account his own $(1774$, p. 143) statement that he "never failed" to make experiments over quicksilver in cases in which the result might be affected by water. He observed the progressive and almost complete disappearance of the inflammable air.

His interpretation was that the formation of the metal from the calx was due to the absorption of the inflammable air, from which he inferred that phlogiston was inflammable air (Priestley 1783, p. 402). This agreed with Kirwan's current view that phlogiston was inflammable air. Priestley stated that he was aware that metallic calces did "usually" contain air that could be expelled by heat, but he hypothesised that the expelling of the air did not regenerate the metal, and that regeneration required the addition of phlogiston. However, his interpretation did not take into account what had happened to the expelled air in this case. Accordingly, he did not take effective account of his own 1774/5 experiments and theories, which had clearly shown and noted that an air was emitted on reduction. He also did not take effective account of his own current experimental finding that he only found the air largely disappearing with inflammable air, while alkaline air disappeared rather less, and this did not happen with other airs.

Following this, in June 1783 Cavendish's assistant Blagden went to Paris, where he informed Lavoisier privately of the results of Cavendish's experiments. Lavoisier quickly issued a paper that dealt thoroughly with Priestley's 1783 experiments, identifying that Priestley had formed water from the combination of his inflammable air with the pure air issuing from his calces, but Priestley had not realised this because his experiment had been conducted over water (Lavoisier 1783, pp. 344-5). ${ }^{30}$

30 As McEvoy (1990, p. 139) noted, Priestley's identification of the identity of phlogiston and inflammable air was due to a "simple experimental error". 
The problems facing any attempt to produce a revised phlogistic theory had now reached a new stage of criticality. There was now sufficient experimental evidence to show clearly the flaws in theories that did not take the evidence into account. Also, it would now be necessary for new phlogistic theories to disagree in whole or in part with competing phlogistic theories. Blagden's trip to Paris had stimulated Lavoisier to deal with the problems of Priestley's (1783) paper, which avoided the need for a fellow phlogistian to do so. Subsequently Cavendish (1784a) comprehensively differed from Priestley's 1774/5 theories and from the two main features of Kirwan's (1782) theories.

\section{Cavendish 1781-1787}

Cavendish's (1784a) paper included several experiments and interpretations of them which differed from Priestley's 1774/5 work. He (1784a, p. 120) concluded that fixed air in calces was not integral to the calces but was present due to being "over the fire or by long exposure to the atmosphere". This differed from Priestley's (1774, p. 193) conclusion that what was contained in calces was pure fixed air, and clarified the mechanisms by which fixed air did enter calces. Cavendish also concluded that neither vitriolic acid nor nitrous acid could be converted into common air, contrary to Priestley's (1774, p. 263 and 1775b, p. 392) hypotheses. Cavendish (1784a, p. 144) stated that mercurius calcinatus "appears to be only quicksilver which has absorbed dephlogisticated air from the atmosphere during its preparation, accordingly, by giving it a sufficient heat, the dephlogisticated air is driven off and the quicksilver acquires its original form". This contradicted several different views that had been voiced by Priestley, and agreed with the views of Lavoisier (1775/8). Cavendish also concluded that "there is the utmost reason to think that dephlogisticated and phlogisticated air, as M. Lavoisier and Scheele suppose, are quite distinct substances, and not differing only in their degree of phlogistication, and that common air is a mixture of the two" (Cavendish 1784a, p. 141). This contradicted Priestley's (1775a, 1775b) views on the two airs.

Cavendish's most notable work in this paper involved an exemplary and careful series of experiments on the combination of dephlogisticated air and inflammable air and on the impurities of phlogisticated air and of fixed air that were involved. He found a small amount of nitrous acid in the experiment, and undertook a set of further experiments to work out what factors influenced the production of the nitrous acid. Nitrous acid was not produced if there was an excess of inflammable air over that required to combine with the dephlogisticated air. If there was an excess of dephlogisticated air, then the amount of nitrous acid depended on the amount of phlogisticated air that was present as an impurity in two ways: when the dephlogisticated air was very pure, introducing a little additional phlogisticated air made the resulting liquid more acid (Cavendish 1784a, p. 138-139), but when atmospheric air was used so that there was a very high proportion of phlogisticated air, less acid was formed (Cavendish 1784a, pp. 133-134). ${ }^{31}$ In effect, Cavendish inferred that the presence of phlogisticated air was essential to the acid being produced, but he implied that a high proportion of phlogisticated air acted to inhibit the reaction between phlogisticated air and dephlogisticated air. These points supported his conclusion that it was "almost decisive" that the small amount of nitrous acid in the experiment on the combination of

31 Cavendish conjectured that this was because the explosion was too weak to provide the heat needed for the formation of nitrous acid under these circumstances. 
dephlogisticated air and inflammable air, was due to impurities of phlogisticated air that were present in the experiment (1784a, p. 138). ${ }^{32}$

In his (1785) paper he reported a set of experiments on some combinations of types of air fired by means of the electric spark. His apparatus involved a small tube and the types of air that he introduced were always underlain by types of liquid each side and then confined by mercury each side. His main experiments were on the combination of dephlogisticated air and phlogisticated air, and these were underlain by "soap lees" ${ }^{33}$ each side. He did several variants of the experiment, and found that there was a volumetric proportion between his two initial airs for which they almost entirely disappeared during the experiment, the result being absorbed by the soap lees. When this was evaporated, the result was nitre. Most importantly, he clarified that nitrous acid was only formed when both dephlogisticated air and phlogisticated air were present, and was not formed when only phlogisticated air was present. Cavendish concluded that the experiments confirmed that in his previous experiments on the combination of dephlogisticated and inflammable air, the nitrous acid had been due to the presence of impurities of phlogisticated air. He prefaced his interpretation by rehearsing his previous conclusions, and stated $(1785$, p. 379) that it was "safe" to conclude that what he had formed was nitrous acid.

Cavendish's experiments on the combination of dephlogisticated air and inflammable air, and on the combination of dephlogisticated air and phlogisticated air, placed even further restrictions on new theories. His own attempts were the first to suffer from this. His (1784a) paper included several theories that were widely disparate. Firstly, as has already been seen, in his views on mercurius calcinatus and on the difference between dephlogisticated air and phlogisticated air, he followed Lavoisier and Scheele by recognising dephlogisticated air as a substance.

Cavendish's theories on acids were very different. They elaborated his own (1766, pp. 145-146) earlier theories that had elaborated on Stahl's (1723, p. 297) views on vitriolic acid, as well as contradicting Priestley's (1774a, p. 263 and 1775b, p. 392) progressions. Yet even though Cavendish had used dephlogisticated air as one of the initial substances in both experiments, these theories did not include it. He (1784a, p. 136) stated that vitriolic acid when united with some phlogiston "forms the volatile sulphureous acid and vitriolic acid air... but when united to a greater proportion of phlogiston it forms sulphur", and that nitrous acid and a certain quantity of phlogiston "forms nitrous fumes and nitrous air... but when united to a different, in all probability a larger quantity, it forms phlogisticated air". It appears to be clear from this quote that when he is talking about vitriolic acid and nitrous acid he means liquid acids, and that by volatile sulphureous acid and nitrous fumes he designates the airs that arise from vitriolic acid and nitrous acid under some circumstances.

Cavendish's (1784a, p. 137) theory of water was different again. In this theory, dephlogisticated air was regarded as dephlogisticated water, which may have been derived from Watt's hypothesis of the previous year. While Cavendish (1784a, p. 141) objected concerning Priestley's view that dephlogisticated air and phlogisticated air differed only in their degree of phlogistication, Cavendish hypothesised that dephlogisticated air and inflammable air differed only in their degree of phlogistication. Cavendish's (1766, p. 145) original view on inflammable air had been that it was phlogiston, and he (1784a, p. 137)

\footnotetext{
32 Saussure (1810) proposed a variation of Cavendish's theory, in which when there was an excess of hydrogen, a little nitrogen combined with both hydrogen and oxygen, forming nitric acid and ammonia, and the ammonia neutralised the acid so that no acidity was apparent (c.f. Murray 1819, v. 2, p. 114).

33 Caustic potash solution.
} 
stated that this was now Kirwan's and Priestley's view, while he now preferred the view that inflammable air was water plus phlogiston. He (1784a, p. 137) attempted to support this by saying that "I know no experiment which shews inflammable air to be pure phlogiston rather than an union of it with water, unless it be Dr. Priestley's experiment of expelling inflammable air from iron by heat alone.... I think it much more likely, that the inflammable air was formed by the union of the phlogiston of the iron filings with the water dispersed among them". Nevertheless, Cavendish had inferred but had not demonstrated that inflammable air contained water. Cavendish had no experimental evidence for his view that dephlogisticated air should be regarded as dephlogisticated water.

Cavendish's new theory of calcination matched Lavoisier's interpretation to the extent that what was absorbed in calcination and what was produced on reduction was dephlogisticated air. Yet it differed in that he hypothesised that the calx contained water, and "as uniting dephlogisticated air to a metal comes to the same thing as depriving it of part of its phlogiston and adding water, the quicksilver may still be considered as deprived of its phlogiston" (Cavendish 1784a, p. 144).

In Cavendish's (1785) paper, he recognised and explained that dephlogisticated air related to his theories in two different ways. His (1785, p. 379) first explanation was that "phlogisticated air ought to be reduced to nitrous acid by being deprived of its phlogiston. But as dephlogisticated air is only water deprived of its phlogiston, it is plain, that adding dephlogisticated air to a body, is equivalent to depriving it of its phlogiston and adding water to it". ${ }^{34}$ His (1785, p. 380) second explanation was that "the phlogisticated air united to the dephlogisticated air, which is equivalent to being deprived of its phlogiston, and was reduced to nitrous acid". Cavendish (1785, p. 379) argued that the difference between his two processes or explanations was that in the first case the result would be more dilute than in the second.

There were several major problems with these theories and explanations. Firstly, the theory of acids was couched in terms of phlogistication, and did not recognise pure air as a substance, even though it had been used in the experiments. Nitrous fumes and nitrous air were both phlogisticated nitrous acid, phlogisticated air was phlogisticated nitrous air and was even more phlogisticated nitrous acid.

Secondly, the relations between nitrous fumes and nitrous air, and between nitrous air and phlogisticated air effectively relied on Cavendish's second explanation, in which pure air was equivalent to deprivation of phlogiston. However, in that explanation, pure air itself could not be accurately represented: it became the absence of the absence of itself-that is, the only way to accurately represent it was as itself.

(1) $+\varphi=-\mathrm{O}$; for the changes from nitrous fumes to nitrous air and from nitrous air to phlogisticated air.

Thirdly, Cavendish's theory that dephlogisticated air was only water deprived of its phlogiston, while fitting with his theory of calces in which "adding dephlogisticated air to a body, is equivalent to depriving it of its phlogiston and adding water to it", was incompatible with (1) above and with his other views on acids which are given in (3) and (4) below. Recast in terms of reduction involving the addition of phlogiston, the explanation is:

$\overline{34}$ Italics have been added to this quote for emphasis. This explanation is wrong for his theory of acids, as will be explained below. 
(2) $+\varphi=-\mathrm{O}+$ water; for reduction.

Fourthly, Cavendish's first explanation was not accurate as it stood. If "phlogisticated air ought to be reduced to nitrous acid by being deprived of its phlogiston" then dephlogistication was equivalent to addition of dephlogisticated air and addition of water, and this was incompatible with his explanation for calcination. Recasting the equation for phlogistication:

(3) $+\varphi=-\mathrm{O}$ - water; for the change from nitrous acid to phlogisticated air.

Fifthly, the relation between nitrous acid and nitrous fumes was different again: in the simplest of these cases, phlogistication meant dehydration.

$+\varphi=-$ water; for the simplest change from nitrous acid to a type of nitrous fume. ${ }^{35}$

Summing up these four points, the problems of Cavendish's theories were much more acute than he recognised in his two explanations. Phlogiston was playing four different roles in his theories. The theory of water was not consistent with the theory of acids. Also, it was not clear why each of his explanations applied to each specific theory.

Sixthly, in the theory of acids, water and calces, substances such as pure air, inflammable air and phlogisticated air were proposed to be compounds, while substances such as water, acids and calces were effectively simple or at least simpler. However, experiments appeared to show that water, calces and acids were decomposable, or at least that they were produced from substances such as pure air, inflammable air and phlogisticated air. Conversely, the latter types of substance could not be shown experimentally to be decomposable. For example, Lavoisier (1776) had shown experimentally that nitrous acid could be decomposed into and recomposed from nitrous air, pure air and water, and (1783) had published that pure air and inflammable air produced water.

Seventhly, every hypothesised compound that hypothetically included phlogiston would contain components that were heavier than itself. The most obvious example was that the lightest substance that was known experimentally, inflammable air, supposedly contained water.

Eighthly, Cavendish (1784a, pp. 137) achieved a resemblance to Stahl's view that water was an element only if water was regarded as physically containing phlogiston, but not if it was regarded as chemically combining with phlogiston. However, in this case even more than in a case of chemical combination, it would be hard to see why the addition of more phlogiston would at some point create a step change between 'dephlogisticated air' and water itself.

Bearing all these difficulties in mind, both Cavendish's experiments and his interpretations are actually strange in ways that may not be apparent on first acquaintance. Although he had a very accurate balance and he (1766, pp. 150-153) had done the pioneering work which found that inflammable air was much lighter than common air and thousands of times lighter than water, and he had investigated whether there was any weight loss when the two airs combined, the remainder of his reported investigations in these two papers involved volumetric analysis, but not analysis by weight. Yet according to his previous investigations on weight, in his view that inflammable air was dephlogisticated water plus phlogiston, phlogiston had to have an enormous effect in terms of making a substance lighter, or phlogiston needed to be almost all of the content of the air. In the latter case, the problem recurred that air saturated with phlogiston was supposed to

35 Cavendish was aware that it was not just one type of air that arose from nitrous acid, but at this stage noone had succeeded in isolating nitrous anhydride. 
suppress combustion, according to Stahl, and it was not clear why an extremely small quantity of water would act to ameliorate that anomaly. Accordingly, Cavendish's theory of water was at least highly improbable.

In his (1785) experiments, he clarified that nitrous acid only arose when both dephlogisticated and phlogisticated air were present, and not when only phlogisticated air was present, but his interpretation was that the nitrous acid came from the phlogisticated air deprived of its phlogiston. He did not attempt to explain why in that case the dephlogisticated air was essential to the formation of the acid. The explanation entailed that the pure air, interpreted as dephlogisticated water, and the phlogiston formed water. This then also showed how crucial to his interpretation it was that in his reported experiments, he always had some form of water present. If he had done his (1785) experiments without soap lees, he would have found some form(s) of nitrous air resulting from the combination, plus some residue of his initial airs. If he had done the experiment using some of his apparatus which allowed him to use sufficient amounts of air that he could have weighed his initial substances and resulting products, he would have found that his nitrous air products weighed approximately as much as the total of his initial dephlogisticated air and phlogisticated air. One or both of these experimental procedures would have demonstrated clearly that his (1784a, p. 136) view that nitrous acid plus phlogiston made phlogisticated air was compositionally inaccurate or at least extremely problematic, and it would have exhibited a problem with Cavendish's (1784a) view that dephlogisticated air was dephlogisticated water.

In sum, Cavendish's (1784a, 1785) experiments resulted in major additions to the available experimental evidence, which crucially affected the whole subject of chemical composition. Yet they also made the creation of revised phlogistic theories even more difficult. His theory of acids showed generically that a new phlogistic theory that did not recognise the role of pure air in calcination had a range of insuperable difficulties. Overall his revised theories were unresolvably inconsistent and unsystematic, and it was effectively impracticable to build a compositional theory based on Cavendish's theories any further. If he had done an experiment on combining pure air and phlogisticated air without water he would have disconfirmed crucial parts of the theory. If he had repeated any of his experiments while including weight analysis, he would effectively have been forced to abandon his theories. He was stuck. In early 1787 Kirwan told Guyton that Cavendish had renounced phlogiston, and Guyton announced this publicly. ${ }^{36}$

\section{Kirwan 1781-1791}

Kirwan (1782, p. 197) firmed up on Cavendish's (1766) theory by arguing that inflammable air was phlogiston. He (1778, pp. 197-203) confidently presented a number of arguments that "proved" his case. He (1778, p. 199) followed Priestley in interpreting that calces were reduced to metals by heating in inflammable air, which they visibly absorbed-but this view was shown to be untenable a year later. He $(1778$, pp. 199, 203) again followed Priestley in arguing that inflammable air was expelled by heating metals including iron and zinc in vacuum conditions. He (1778, p. 200) stated that calces were never restored to metals except by substances containing the inflammable principle, which

\footnotetext{
36 In the postscript of the letter from Kirwan to Guyton on 2 April 1787, Grison et al. (1994, p. 167). Guyton published this in his reply to Kirwan $(1789$, p. 298). Cavendish was the first to sign the certificate dated 3 April 1788 which admitted Lavoisier as a foreign member of the Royal Society (Jungnickel and McCormmach 1999, p. 377).
} 
did not take into account that in 1775 Priestley had reduced minium and mercurius calcinatus over mercury in closed conditions with no air or other substances present. He (1778, p. 199) stated that metals which dissolved in acids with the evolution of inflammable air also displaced other metals from solutions of their salts without evolution of this air, and interpreted that the inflammable air emitted by the displacing metals was absorbed by the displaced metals.

Concerning the problems that have been identified in section "Cavendish and Guyton, 1766-1772" concerning Cavendish's theory that phlogiston formed inflammable air, Kirwan solved the weight issue in the same manner as Priestley (1774) and Macquer (1778), by theorising that air was absorbed in calcination. He did not address the issue that Stahl's theory was that air saturated with phlogiston suppressed combustion. He (1782, pp. 197-198) argued that inflammable air was present in all inflammable substances - it had been obtained from grease and wood by Hales, by Fontana from charcoal, by Priestley from resins and spirit of wine, and so on; he acknowledged that the smell of inflammable air was different from different types of substance, but argued that this was due to impurities. He did not address the issue that inflammable air did not act as a reducing agent fully in the same way as charcoal, or as focussed light. He (1782, p. 201) stated that sulphur was produced when concentrated vitriolic acid was distilled with iron or bismuth and interpreted that inflammable air converted vitriolic acid into sulphur; this argument did not take weights into account.

Scopoli (1786, pp. 7-8) rejected the identification of inflammable air with phlogiston. His grounds included that metals produce no inflammable air on calcination, that inflammable air did not actually produce sulphur with vitriolic acid, and that there were different kinds of inflammable air but there was only one kind of phlogiston.

Kirwan (1782) also followed Priestley (1774, p. 193) in arguing that calces contained fixed air, which did not take into account Priestley's experiments in which he produced pure air from minium and mercurius calcinatus. Kirwan's views on inflammable air and on calcination fundamentally differed from Cavendish's (1784a) experiments and theory, and Kirwan (1784a) defended his views by hypothesising that inflammable air could combine with respirable air to form water at high temperature or fixed air at some lower temperatures (Kirwan 1784a, p. 167). Kirwan's (1784a) theory involved the odd asymmetry that although pure air was absorbed in calcination, in general fixed air was expelled in reduction, except in the cases of mercurius calcinatus and minium (Kirwan 1784a, p. 154). In Kirwan's theory, vital air only became the acidifying principle and a constituent part of calces after it had united with inflammable air to form fixed air (Kirwan 1789, p. 286) and that only acids united to other substances (Kirwan 1789, p. 314), despite the fact that his view also involved inflammable air uniting to other substances such as the bases of metals, sulphur and phosphorus. Kirwan's hypotheses on acids included (1789, p. 126) that marine acid consisted of a peculiar basis united to phlogiston and a certain proportion of fixed air, while dephlogisticated marine acid consisted of the peculiar basis with an excess of fixed air.

Kirwan (1789, p. 284) identified one of the flaws with Cavendish's new theory by making the reasonable empirical point that inflammable air "may be deprived of its water without any limitation, and yet preserve all its properties unaltered, which shews the presence of water to be no way essential to it." However, Kirwan (1784a, pp. 155-157) rejected Cavendish's (1784a, p. 120) proposal that experimental errors might arise due to the fixed air in the atmosphere, giving the inadequate reason that this was in a very small proportion. ${ }^{37}$ Kirwan (1784a, p. 160) stated that there was no substance which yielded

37 Clearly this reasoning was not adequate, and reasonably long exposure to air would facilitate the absorption of considerable quantities of fixed air from the atmosphere. 
dephlogisticated air but also yielded fixed air first. This did not answer Cavendish's point that the fixed air was due to impurities of some form in the substances rather than due to the properties of the basic substances involved, it did not take into account Priestley's (1775a, p. 49) view that care was necessary to extract fixed air from calces before experimenting, and did not take into account that Lavoisier (1775/8) had shown that fixed air was formed from the combination of pure air and charcoal. Kirwan opposed Cavendish's statement that fixed air had never been produced in reduction in closed conditions with the very noteworthy claims that it was difficult to perform experiments in closed conditions and that there was "clearly" no significant difference between performing the experiment in closed or open conditions (Kirwan 1784a, p. 158), which did not take into account that both Cavendish and Lavoisier routinely performed experiments in closed conditions in order to minimise the experimental errors that did arise in open conditions. Cavendish (1784b) and Kirwan (1784b) continued the argument.

The arguments between Cavendish, Kirwan and Priestley aided the cases of the Lavoisians. In their replies to Kirwan, the Lavoisians (in Kirwan 1789) proposed possible experimental errors that in some cases were those that had already been advanced by Cavendish. Also, Guyton amplified Cavendish's criticisms by noting that Kirwan's claims depended absolutely on the proofs of the existence of inflammable air in sulphur, phosphorous, nitrous gas, metals and charcoal (Kirwan 1789, p. 286), and that Kirwan's use of the modifying clause- "unless it should be proved that those substances contained no inflammable air" - clarified that Kirwan's arguments were by analogy only and did not demonstrate the necessity or the reality of the existence of phlogiston, or of inflammable air, in these bodies (Kirwan 1789, p. 288).

Kirwan's and Macquer's theories show generically that a revised phlogistic theory which did take into account the role of pure air in calcination, and also tried to identify phlogiston with an experimentally observable substance or entity, had the generic problem that this version of phlogiston could not be experimentally demonstrated to be a constituent of substances of which the theory stated it was a constituent. Like Cavendish but for different reasons, Kirwan was now stuck. In 1791 he wrote two letters ${ }^{38}$ in which he publicly admitted that he could not provide a clear experimental demonstration that pure air and inflammable air combined to form fixed air, and that consequently he could not show that metals contained inflammable air. He stated "Enfin je mets bas les armes et j'abandonne le ph[logis]tique".

\section{Scheele 1785}

Following Lavoisier's (1782) criticisms and Lavoisier's (1783) paper that implicitly showed how Scheele's (1931, p. 97) main experimental mistake had occurred, Scheele (1931, pp. 283-295) produced a revised phlogistic theory. This involved one type of strategy for attempting to deal with the criticism that in the former phlogistic theories, the differences between very diverse substances were explained as depending on only on a little more or a little less phlogiston. This new strategy was to rely on more than one fundamental and unisolatable principle in addition to water and to an unspecified number of types of experimentally-unavailable earth. Scheele's additional fundamental principle was the "saline principle". Scheele (1931, p. 286) gave the opinion that "it is very probable that if we could entirely deprive of water the acid of nitre, this acid would then

38 One was to Berthollet, given in Lavoisier (1997, p. 227). The other was to Crell, given in Grison et al. (1994, pp. 198-199). 
approach very nearly to the saline principle". ${ }^{39}$ That is, although this principle and phlogiston were both ponderable in Scheele's theory, they weren't currently experimentally accessible. This view of acidity differed from Stahl's view, Macquer's view and Sage's early view that the universal acid was vitriolic acid. ${ }^{40}$ In this theory, neither water nor heat was the cause of the elasticity of air and of vapours, which was caused by phlogiston (Scheele 1931, pp. 286-287).

Scheele (1931, p. 286) proposed that heat and light were combinations of the saline principle with phlogiston. Scheele (1931, p. 287) stated that inflammable air also consisted of the saline principle and phlogiston, and he (1931, p. 334) also said that inflammable air was a mixture of phlogiston and the matter of heat. Scheele (1931, p. 287) water was the chief cause of the weight of the air, and the lack of it was why inflammable air was so light. He (1931, p. 286) proposed that fire air consisted of the saline principle, a small quantity of phlogiston, and some water.

Scheele's (1931, p. 288) new proposal for the combustion of phosphorus was that the saline principle in the fire air united with as much phosphorus as is necessary for fire; this fire disappeared together with the specific heat which the air had previously absorbed; but the water which was now abandoned by this saline principle united with the acid of phosphorus; and this was the explanation of the increased weight.

Scheele's (1931, p. 287) new explanation for the result of the kindling together of inflammable air and fire air was that the saline principle of the fire air at once attracted the phlogiston of the inflammable air; from this, heat was composed as well as light. The specific heat of both species of air was simultaneously set at liberty; this fire penetrated through the glass. The water, abandoned by the fire air and the saline principle remained behind and collected into drops.

This revision was still subject to Leonhardi's (1790, v. 6, p. 604) later objections. As previously stated, given that neither air nor phlogiston could pass through glass, it was not credible that their compound should do so. Secondly, there was no change in weight when combustion occurred in closed vessels. Leonhardi judged that Scheele's theory had "lost all approbation".

There were several other problems with this theory. It did not specify what was the constitution of metals and acids other than nitrous acid, and elaborating a more detailed chemical nomenclature would have made the theory look less plausible. It also did not specify how heat functioned in the theory-Scheele knew that latent heat was necessary for change of state, but heat did not cause the gaseous state in this theory. Each gas was hypothesised to contain at least one constituent substance that was heavier than itself, while fire air was hypothesised to contain two such constituents.

\section{Priestley 1785-1791}

Priestley's late phlogistic theory differed fundamentally from Cavendish's and Kirwan's theories, although in a few ways it paralleled or echoed Scheele's late theory. Priestley (1785, p. 288; 1786a, p. 87; 1788a, p. 152) accepted Cavendish's view that inflammable air consisted of water plus phlogiston. However, he (1788b, p. 314) differed from Cavendish's view on dephlogisticated air, now hypothesising that dephlogisticated air consisted of water plus the "principle of acidity". The latter concept was not the same as Scheele's "saline principle", but Priestley's theory was like Scheele's in that from 1788 to 1793 it

\footnotetext{
39 This appears to imply that his principle was probably, in modern terms, $\mathrm{N}_{2} \mathrm{O}_{5}$.

40 Juncker (1757, v. 5, p. 62), Macquer (1764, p. 23), Sage (1772, pp. 1-2).
} 
involved two unisolatable principles in addition to water and several earths, although both of Priestley's unisolatable principles might or might not be ponderable.

His exposition of the theory started from the experiment in which dephlogisticated air and inflammable air were exploded together, and from the interpretation that the nitrous acid, which according to Priestley $(1789$, p. 7) was always formed in the experiment, was an integral result of the experiment and was not due to impurities. Priestley (1788a, pp. 151-152) argued that his initial airs were "exceedingly pure", and on this basis his (1788a, p. 154; 1790c, p. 535) theory was that water was not decomposed, and (1788a, p. 151) that the nitrous acid was formed from the phlogiston and the "principle of acidity". When he later stated that those ingredients also produced other results, he stated that nitrous acid is formed "if [dephlogisticated air and inflammable air] have been previously formed and then decomposed together" (1789, p. 12; 1790c, p. 536; 1796, p. 51).

There were objections to this theory from the outset. ${ }^{41}$ In response to one, he (1789, pp. 11-12) added the supplementary hypothesis that the fixed air in the experiment was also not due to impurities and was formed from phlogiston and the "principle of acidity". He proposed that this happened if one of his input substances "is decomposed from some other substance" (1789, p. 12; 1790c, p. 536).

Yet Priestley (1775a, p. 49) had previously stated that it was necessary to extract fixed air from his airs beforehand, and he (1775a, p. 217) had identified that fixed air was always contained in common air, that it was always contained in dephlogisticated air, and that when dephlogisticated air was procured by any process whatever, there was always a considerable quantity of fixed air mixed with it. Lavoisier (1777a, p. 141) had noted that "pure" air was never obtainable entirely free from impurities of mofette, and (1777c, p. 197) that fixed air was also present as an impurity in calces. Cavendish (1784a, p. 120) had shown that fixed air was present in this type of experiment as an impurity and (1784a, p. 138) had shown "almost decisively" that the nitrous acid was due to impurities of phlogisticated air in the experiment, while (1785) nitrous acid arose during the combination of dephlogisticated air and phlogisticated air. There continued to be objections that Priestley's results were due to impurities, and that there were circumstances in which nitrous acid was not formed in this type of experiment.

Priestley continued to add supplementary hypotheses to deal with difficulties and objections. An explanation was required for why the result of the experiment could be water. Priestley $(1789$, p. 8) proposed that if this happened, the acid formed from the principle of acidity and phlogiston might have wholly escaped because of its extreme volatility. This escape might also happen to part of the acid when any of the other substances were produced (Priestley 1789, p. 9). Some phlogisticated air was also sometimes present in the results of his experiment, and Priestley now decided that this was also not due to an initial impurity but was formed by the substances in the experiment. So the principle of acidity and phlogiston and water could also form phlogisticated air (1791, p. 221), and this happened "if there be a redundancy of inflammable air in the process". Priestley did not explain why in some cases this was the result and in other cases the phlogiston and principle of acidity escaped and only water was the result. He also added that these components could form nitrous air. He stated that nitrous air "consists of phlogiston, and some portion of the acidifying principle, combined in a very peculiar and unknown manner" (1790c, p. 536). He also stated that all gases contain water, and that

41 Priestley 1789, p. 7. C.f. Priestley's letters to Wedgewood, Priestley 1892, pp. 91 and 95. C.f. Berthollet 1789, pp. 67 and 89). 
"nitrous air and fixed air, consist of the same elements differently combined" (1790a, p. 133$).^{42}$

Unlike Cavendish's, Kirwan's and Scheele's theories, Priestley's new theory did not have a settled explanation for calcination. Priestley (1774, p. 193) had interpreted that calces contained fixed air. He (1775a, pp. 33-34) had produced dephlogisticated air from several calces including red precipitate, and he (1775b, p. 392) interpreted that dephlogisticated air consisted of nitrous acid and earth and the least possible phlogiston. He (1788a, p. 155) heated red precipitate in inflammable air and found water, so he hypothesised that red precipitate contained water. In total contrast he (1790c, p. 546) stated that if precipitate per se was heated in inflammable air, fixed air [not water] was "always" formed. ${ }^{43}$

Shortly afterwards, he (1793, p. 38) stated that "the nitrous acid, nitrous air, fixed air, phlogisticated air, alkaline air, and probably all the other kinds of air with which we are acquainted, except the dephlogisticated and the inflammable, are composed of dephlogisticated air and phlogiston”. In Priestley's chemistry textbook he (1794, pp. 8-9) expanded this into the speculation that "all the appearances that have yet occurred to us" could be explained in terms of the "elements" which appear to "compose all natural substances, viz. dephlogisticated air, or the acidifying principle; phlogiston, or the alkaline principle; the different earths, and the principles of heat, light, and electricity. Besides those, there are the following principles which have not been proved to be substances, viz. attraction repulsion and magnetism". He did not explain in detail how other substances were composed from these "elements".

In Priestley's late theory, the very substantial differences between several sorts of air were due to different proportions of phlogiston and the principle of acidity, which might or might not be ponderable. At first he (1788a, pp. 149-150) had argued that his water did not weigh as much as the total weight of his airs, which implied that at least the principle of acidity was ponderable, ${ }^{44}$ but later he (1800, p. 46) argued that water might constitute the whole of the weight of dephlogisticated air and inflammable air, without then revising his explanation concerning why he did not obtain as much water as the total weight of his airs. Some of his conclusions assumed that phlogiston and the principle of acidity were retained by the glass, while others assumed that they could go through the glass $(1789$, p. 8). All these points meant that his views were, in principle, indefinitely defensible against almost any experimental evidence. However, this was no longer a sufficient condition for viability as a competitive theory - a viable competitive theory now not only needed to match the explanatory range of the theory with which it was competing, but also needed to be sufficiently experimentally testable so that it could be assessed, adopted and developed by other people, and this was not achieved by any of Priestley's (1791, 1793 and 1794) mutually-inconsistent versions of his theory. Accordingly, none of them were adopted by other leading phlogistians.

\footnotetext{
${ }^{42}$ Priestley (1790b, p. 46), stated that "we took it for granted, that it consisted of nitrous acid and phlogiston".

43 This was probably another of the instances in which Priestley was using heavy inflammable air. The oddity is that he stated that he always obtained this result, when clearly he had recently obtained water when using light inflammable air.

44 Priestley (1788b, p. 314), argued that about one-twentieth part of dephlogisticated air was the acidifying principle. He (1790c, p. 535), then argued that water "seems to constitute about nine parts in ten of dephlogisticated air.
} 


\section{Gren 1786-1790}

This section is a very brief summary of matters which will be considered in more detail in a subsequent paper. Gren's first phlogistic theory, perhaps more than any of the other late phlogistic theories, started from theoretical considerations and not from experiments. His objective was to rescue the "German" phlogiston theory of Stahl. In order to do so, he took the drastic steps of denying matters which almost everyone else thought had been established by experiment.

He (1788, p. 344) stated "I deny, on more than one ground, embodied or fixed air, and assert that all aëriform fluids of this kind on their development are either generated or first arise from their components". This left him with the original Stahlian weight issues concerning calcination. He (1793, p. 32) continued to assert that the weight of a body measures only the part of the body which is gravitating and there is no proof that gravity acts on all the material parts of the body, and then attempted to solve the weight issue by re-asserting the absolute levity of phlogiston, which Venel had proposed in France thirty years earlier. 'Ribapotme' (1768) had argued against Chardenon that physicists would rightly object to such theories, and it was the objections of the physicist Mayer that led Gren to abandon this version of his phlogistic theory in 1790 .

As was the case with Priestley's late theory, the conditions in which Gren's theory was produced had changed relative to those in which Stahl's theory had been produced. While experiments were not "crucial" in the Baconian sense, Hermbstädt's repeated success in producing pure air from mercurius calcinatus, and the lack of experimental support for Gren's contention that no such air was produced, became important in terms of theory choice in Germany.

\section{Theories on phlogiston and electricity 1781-1791}

During this period, it continued to be the case that a link between the concepts of phlogiston and electricity was speculative, so that there was no agreement among those who supported a link, and no such link was supported by the main phlogistians in France and Britain during this period.

Fontana (1784, pp. 150-151) argued that, contrary to the views held by most writers on the topic, the electrical matter was not simple, but it was a real substance in combustion, which had the same effects on common air as phlogiston or actual flame. In 1785, Van Marum (1974, pp. 48-50) undertook experiments which showed that several metallic calces were revived by electrical discharges. Given the chemical teaching that calces could be revived other than by imparting phlogiston to them, he (1974, p. 50) concluded that the electric matter either was or contained phlogiston.

By contrast, Cavallo (1786) commented that van Marum's experiments showed that electrical discharges produced both the apparently contradictory effects of calcination and reduction, and maintained his conclusion that the electrical fluid was not phlogiston. Just after this period, Priestley (1794, pp. 8-9) stated that electricity and phlogiston were separate fundamental substances. 


\section{Brief notes on implications for the methodologies of the history of science}

To get a full picture of the phlogistic theories and their potential, it is necessary to analyse the chemistry itself. In sections "Phlogiston and related problems before 1766"-"Phlogistic theories and their problems, 1781-1791" of the current paper, this has been done in the context of the chemistry of the time, that is, non-Whiggishly.

Examination of science in this way does not involve the "triumphalist" "glorification of the present", nor does it involve a Manichean struggle between the forces of light and dark, and between "good guys" who are on the side of truth that is now known and "bad guys" who opposed the emergence of it. Nevertheless the normal process by which theories were developed and assessed during this period involved what can be seen as a struggle for survival. The analysis of the chemistry of the theories that were unable to adapt, demonstrates why the surviving theory did survive, and does not constitute "bias" against the "losers", nor does it involve the assumption that the "losers" were "ignorant" or irrational.

Methodologies of the history of science that do not involve analysis of the science tend to fail to grasp, or to act to conceal, what was actually the better scientific theory or practice at any point in time. The method of analysing individuals' aims and views in the context of their own time gives some useful information, but it fails to take into account matters that they chose to conceal and matters that they did not understand, and the aims and views that are analysed may partly or wholly omit the chemistry. It is necessary to take into account the work of several of the main participants, but a noteworthy segment of the secondary literature views the period 1770-1805 in chemistry largely in terms of a clash between Priestley and Lavoisier together with his followers. ${ }^{45}$ The contextualist maxim that science cannot be understood other than in its wider intellectual context can also be counter-productive to understanding what went wrong or right with the science itself. Science is developed by individuals or groups in societies, and the social aspects of science are important. The present paper has illustrated quite how much interaction there was among the main participants. However, the current trend towards the writing of "loser's history", which has included adopting "lock, stock and barrel the phlogistonists' actors' sociology" (Kusch 2015, p. 78) and arguing that the winners imposed their theories by elitist and extra-scientific strategies, has not led to a good understanding of why chemistry rationally developed as it did.

\section{A brief survey of selected themes in the secondary literature}

The period of the phlogistic theories has proved to be a minefield for historians. The more that the detail of the phlogistic theories is taken into account, the more it is seen that almost any generalisation that purports to be about a single overarching "phlogiston theory" is inaccurate. Arguments that assume that the individual phlogistic theories were internally consistent are particularly inaccurate in the cases of Cavendish's and Priestley's theories, as is now shown in sections" Cavendish 1781-1787" and "Priestley 1785-1791" above.

\footnotetext{
45 This includes much of the literature from what has been labelled the "positivist-Whig" period and also literature from subsequent periods in the history of science, including McEvoy (1978-9, 1983, 1987, 1990), Holmes (2000) and Chang (2009, 2012).
} 
There are many works that recognise that there was a plurality of fundamentally differing late phlogiston theories. ${ }^{46}$ Kopp's history was outstanding for its time in not having a nationalistic bias on these subjects, and he (1845, p. 155) stated that during this period "there was only agreement concerning the existence of something called phlogiston.... This situation of true anarchy lasted among the phlogistians from about 1780 to 1800". In Partington's indispensable history, he (1962, p. 605) judged that "from about 1770 the latest developments of the theory agree only in their difference from the opinions of Stahl". Musgrave (1976, p. 188) suggested that the Lakatosian "hard core" of the research programme of phlogistic theories was the hypothesis that combustion and calcination involved the release of phlogiston. The present paper, following Kopp and Partington and taking into account that in the late phlogistic theories of Cavendish, Kirwan and Priestley phlogiston was retained in calces, judges that all that was reliably left in the "hard core" was the word "phlogiston".

There is a loose tradition following from Kopp (1843, pp. 151-152), who thought that in the earlier part of the period, phlogiston was a negative version of oxygen. Partington (1962) pointed out that this was too simple. ${ }^{47}$ The correlation was explicitly proposed by Cavendish (1785, p. 380) in connection with his developed theory of acids. Yet it was only one of his inconsistent theories of what phlogiston was, and his late theories had many problems as detailed in section "Cavendish 1781-1787". These problems are little recognised in the secondary literature: none of them was identified by Thomson (1830, v. 1, pp. 347-8), Jungnickel and McCormmach in their very useful biography of Cavendish (1999, pp. 362-367), or Partington (1962, pp. 329-342). Partington (1962, p. 342) quoted Cavendish's proposed reconciliation of his explanations for how phlogiston related to pure air without picking up on the problems of the differences between the theories. Partington (1962, p. 334) argued that in Cavendish's (1784a, p. 137) view that pure air was dephlogisticated water, water was a simple body, without explaining how phlogiston could be taken away from a simple body, and even though he recognised that Thorpe (in Cavendish 1921, v. 2, p. 35) had said that Cavendish did not think that water was simple. Meyer (1891, p. 118) recognised the weight problem. Paul (in Watts 1872, v. 2, p. 780) pointed out that in Cavendish's view, water was a constituent of each air that was a constituent of water, and the two kinds of air were "supposed to be, at the same time, equally air and equally water." Siegfried (1989, p. 37) stated that "though I have stressed the formal equivalence of the phlogistic and the antiphlogistic descriptions of the same chemical behaviour, I by no means intend to imply that the two modes of expression were of equivalent scientific value. On the contrary, the difference between them was what made Lavoisier's triumph possible. Where Bergman was calculating the relative value of the impalpable phlogiston, Lavoisier was calculating real values of ponderable oxygen". However, the analysis in section "Cavendish 1781-1787" and the divergences between the late phlogistic theories show that phlogiston and negative oxygen were far less equivalent than Siegfried proposed.

There is another loose tradition following Kopp (1843, p. 151), who thought that in the later part of the period, phlogiston was hydrogen. However while Cavendish (1766)

\footnotetext{
46 Including e.g. Fourcroy (1796, p. 454); Dumas (1878, p. 161), McEvoy (1988, p. 198), Abbri et al. (1984), Boantza and Gal (2011, p. 5), Needham (2013, p. 86); Kusch (2015, p. 74 and 78). By contrast, works that argue that there was $a$ phlogiston theory or system have included McEvoy (1997, p. 22) and Chang (2012, e.g. p. 31).

47 There are many authors who have not recognised the problems of the proposed equivalence of phlogiston and negative oxygen, including Rodwell (1868, p. 25), Musgrave (1976), Holmes (1995, p. 19), McEvoy (1997, p. 22) and Klein and Lefèvre (2007).
} 
proposed that phlogiston formed inflammable air, he changed his theory in 1784 . The objections of Scopoli (1786) to the theory that phlogiston was inflammable air are stated in section "Kirwan 1781-1791". Kirwan was the only participant who defended the identification of phlogiston and inflammable air from 1782 to the end of the decade. Of the problems listed in section "Cavendish and Guyton, 1766-1772" concerning Cavendish's (1766) theory, the second was is stated by Musgrave (1976, p. 190) and Meyer (1891, p. 118) recognised the first. Concerning the fourth problem, Rodwell $(1868$, p. 26) noted that the properties of Stahl's phlogiston were "utterly different" from those of hydrogen in many respects. None of these problems was identified by Thomson (1830, v. 1, pp. 340-3), Partington (1962, pp. 312-315) or Jungnickel and McCormmach (1999, pp. 205-208). Stewart (2012, p. 178) argues that "during the $1780 \mathrm{~s}$, phlogiston occupied the same laboratory reality and often the same laboratory bench as oxygen". On the contrary, while inflammable air occupied the same laboratory reality as oxygen, phlogiston did not, as Kirwan effectively admitted in 1791. Stewart (2012) argued that phlogiston was real and non-Stahlian in Britain in the $1780 \mathrm{~s}$, but in actuality both Cavendish and Priestley were in the process of adopting more Stahlian features in their views, and neither Cavendish nor Priestley fully accepted the view that phlogiston was inflammable air after 1783. Also, Kirwan's view was still Stahlian in that phlogiston in the form of inflammable air was still supposed to be present in metals, sulphur, phosphorus and carbon. Some accounts have recognised that the main late phlogistic views continued or returned to some extent to the use of a "rudimentarily" Stahlian general principle. ${ }^{48}$

On another issue that relates to Cavendish's work, Popper and Lakatos argued against the practice of "shrinking from making experiments that have a chance of refuting" cherished beliefs, and later authors such as Chang (2012, p. 222) have agreed. Yet although Cavendish was an outstanding expert on weight analysis, he did not investigate his (1784a, 1785) experiments in terms of weight. He also did not undertake his (1785) experiments without water present, and either of these types of experiment would have at least undermined his phlogistic theories.

There are differences concerning what principles were supposed to be and then concerning to what extent the phlogiston systems were based on particular views about principles. One argument is that laboratory practice with principles involved the transformation of other substances, whereas compositional practice involved the decomposition and recomposition of substances (Chang 2012, p. 40). Yet in the textbooks of the main phlogistians, chemistry is defined as involving the decomposition and recomposition of substances (Stahl 1730, p. 1; Juncker 1757, pp. 1-2; Macquer 1764, p. 1). Stahl's phlogiston was originally one of his three earths-vitrifiable, inflammable and mercurial concerning which he (1730, p. 13) stated that each earth was "a body, solid of itself, the most fixed, and the foundation of fixedness in aggregates and atoms". Boantza and Gal (2011, pp. 330-2) argued that for the phlogistians, "aerial entities transmuted into one another with the loss and gain of phlogiston", but these points are not accurate with respect to Kirwan's and Cavendish's theories, nor Priestley's late theory. Boantza and Gal (2011, p. 333) argued that although Priestley's airs were distinguished by degree of phlogistication, they were nevertheless distinct substances, yet Cavendish (1784a, p. 141) had objected that dephlogisticated and phlogisticated air were "distinct substances, and not differing only in their degree of phlogistication”. Boantza and Gal (2011, p. 329) argued that "like Kirwan, Priestley did not deny that water was a compound that could be

${ }^{48}$ E.g. Priestley (1794, pp. 8-9). C.f. McEvoy (1983, p. 52, 1987, p. 65, 1988, p. 201, 1990, p. 139-140). 
decomposed and recomposed, analysed and synthesised", but Priestley (1788a, 1788b, 1789, and 1791) did argue that water was not decomposed.

Concerning Priestley's 1772 experiments on calcination, Partington (1962, p. 255) noted that "there was, of course, no fixed air produced". Schofield (2004, p. 102) noted more generally that "Priestley, seldom regarding any part of a reaction except in the airs he was studying, often missed significant variations in other parts of his processes", which applies to these experiments. Concerning those experiments and his 1774 experiment on reduction, McEvoy (1978, pp. 99 and 111) noted that phlogiston was epistemologically unwarranted in Priestley's epistemology, but he and Schofield (2004, p. 99) did not note that the 1774 experiment removed nearly all the grounds that underpinned Priestley's (1774, p. 282) standard phlogistic view that the difference between metals and metallic calces had to be due to the transference and presence of a "real something" which he regarded as corroborating the existence of phlogiston, even though he now knew that there was a different real something that was transferred and which was a constituent of calces. Partington (1962, p. 256) did not mention the 1774 experiment on reduction. None of Partington (1962, p. 257-260, McEvoy (1978, pp. 166168 ) and Schofield (2004, p. 112) identified the problem that Priestley's (1775a) name "dephlogisticated air" was inaccurate concerning the experiment in which Priestley had first discovered the air. Musgrave (Musgrave 1976, p. 205) argued that Priestley's (1783) paper involved "the most impressive experiment of all" but McEvoy (McEvoy 1990, p. 139) rightly noted that Priestley's (1783) experiment involved a "simple experimental error".

Concerning Priestley's (1788a, 1791) theories on water and types of air, Black (1803, pp. 541) stated that "it is... difficult to procure vital air perfectly pure, and, especially, free from azote... I call your attention to this circumstance, because many of Dr. Priestley's experiments, by which he still thinks that the theory of Stahl is supported, have had results which were certainly owing to such impurities". Thomson (1830, v. 2, p. 22) stated that Cavendish's (1784a) facts concerning nitrous acid in the experiment "invalidate the reasoning of Priestley altogether; and had he possessed the skill, like Cavendish, to determine with sufficient accuracy the proportions of the different gases in his mixtures, and the relative quantities of nitric acid formed, he would have seen the inaccuracy of his own conclusions". Schofield (1964, p. 289), inaccurately argued that "the experiments of Priestley, of Cavendish and of Lavoisier and his adherents report that an acid was obtained, not simple water". Schofield (2004, p. 183) did not identify that Cavendish's (1784a, p. 138) work showed where Priestley's (1788a, 1791) theories were inaccurate. Schofield (2004, p. 192) wrongly argued that Cavendish's methods of solving the problems with the water experiment were "unavailable to the new chemistry", whereas due to Cavendish's (1784a) paper the Lavoisians knew how the problem could be solved by early March 1785, and they applied one of the methods in 1790-1 (Séguin 1791). However, Schofield clarified concerning Priestley's (1794, pp. 8-9) theory that "Priestley had previously argued against most of these positions and would, typically, argue against any one of them in subsequent years". There is a large number of problems with Verbruggen's (1972) position, of which the most general are that both Cavendish and Lavoisier knew that inevitably there were impurities in the experiment, whereas Priestley's theory crucially depended on there being no impurities in his experiment, and that while Cavendish's (1784a) findings solved the problem with Lavoisier's experiment, one of them (1784a, p. 138) was directly contrary to Priestley's theory and Priestley never acknowledged or solved this problem. 
It often been recognised that Cavendish, Kirwan and Priestley subscribed to empiricist methodologies (e.g. McEvoy 1988, p. 198). However, as McEvoy (1978, p. 99) pointed out, references to phlogiston were rationally unjustifiable on Priestley's empiricist epistemology, so that Priestley should have regarded phlogiston as no more than a heuristic hypothesis designed to promote further experiments, whereas in practice he mostly did not go on to test his phlogistic hypotheses.

Many important chemical discoveries were made in the period of the phlogiston theory, but Partington (1962, p. 605) judged that they cannot be shown to have developed from the theory. Rappaport (1961, p. 73) indicated that the modern retrospective view that phlogiston epitomised eighteenth-century chemistry before Lavoisier would have surprised Rouelle, for whom it was one component of a more comprehensive theory. This needs to be set against such inaccurate views as Crum Brown's (1866, p. 328) judgement that "for more than a hundred years it was recognised by all as the foundation of the science".

Kitcher (1993), Musgrave (1976) and Pyle (2000) rightly noted that from 1783 the remaining phlogistic theories were unable to cope with experimental evidence. None of these writers noted the full range of fundamental divergences between the late phlogistic theories and the variety of problems that they encountered, yet in each case their overall lines of argument are bolstered by the material in the current paper. Kitcher (1993, p. 277) rightly noted that some phlogistians' attempts to retain phlogiston, even while accepting the absorption of air during calcination, ran into dead-ends, and in particular that Kirwan's strategy ended in tangles and inconsistencies. Kitcher's overall argument is further confirmed by the analyses of the problems with Cavendish's and Priestley's late theories that have been given above. Musgrave (1976) rightly identified that after 1770 neither did the phlogistic theories develop coherently nor was each version theoretically and empirically progressive. Musgrave's (1976, pp. 203-206) argument that from 1783 on the phlogistic theories were forever on the back foot is confirmed by the additional detail in the present paper. Musgrave (1976) argued that Cavendish's (1784a) “theory" was not refuted by experiment, but section "Cavendish 1781-1787" in the current paper has shown that Cavendish's paper involved several inconsistent theories, and also that Cavendish (1784a, 1785) did not use his own experimental methods that would have invalidated his theories. Pyle (2000) rightly pointed out that the problems of the late phlogistic theories became particularly acute when they tried to retain phlogiston in addition to recognising the absorption of oxygen in calcination.

There have been some retrospective views concerning what phlogiston could have been, which have taken into account modern science but which have not taken into account what the phlogistians actually said. Crum Brown (1866, p. 328) inaccurately argued that "there can be no doubt that [potential energy] is what the chemists of the seventeenth century meant when they spoke of phlogiston", whereas for Stahl and the later phlogistians, while phlogiston was labelled as a principle, it was a substance and a component of other substances. Odling (1871) argued that Becher and Stahl were indifferent to the weight issue, whereas Rodwell (1868, p. 30) noted that the phlogistians were aware of the weight issue but "generally omitted [it] from their handbooks". Odling (1871) argued that Becher and Stahl were "altogether ignorant" of the part played by air in combustion and calcination, but Stahl was at least aware of the work of Boyle and disagreed with it. Odling did not take into account the work of authors such as Rey and Mayow on the involvement of air, and inaccurately stated that the idea of types of air being constituents of solid matter was established by Black, Cavendish and Bergman. Odling (1871) inaccurately argued that "men like Priestley and Cavendish... pointed out... that combustible bodies possess in common a power or energy... and... that the energy pertaining to combustible bodies is the 
same in all of them". Odling attempted to justify this view from the explanation of Watson (1781, p. 167) that the expectation of finding a handful of phlogiston was as unreasonable as demanding a handful of magnetism, gravity or electricity. But Cavendish did not consider that there was a link between phlogiston and any of magnetism, gravity or electricity, and during the period between 1775 and 1802 Priestley did not produce any speculations concerning a link between phlogiston and electricity. Odling argued that Stahl "establishes what may be called the permanency of chemical substance" but nevertheless argued that phlogiston was a form of energy. The latter view does not take into account most of what phlogiston was historically supposed to be: for example, it is not the case that carbon and inflammable air differ from other substances by being almost completely potential energy, nor that the diminution of air in calcination is due to saturation with potential energy, nor that nitrous acid plus potential energy makes nitrous air, while nitrous acid plus a different quantity of potential energy makes phlogisticated air, and so on. Odling (1871) then argues that the phlogistic and antiphlogistic views "are in reality complementary". However, the present paper has shown that if phlogiston was regarded as negative oxygen, it was inevitably in competition with oxygen for a place in chemistry, while when it was admitted that oxygen was absorbed in calcination, there were no options for a new view of the nature of phlogiston were which testable and in which phlogiston could be found experimentally in the substances of which it was supposed to be a component. $^{49}$

Another example of a counterfactual view of what phlogiston could have been is the view of Lewis (1926, pp. 167-168) that if the phlogistians "had only thought to say "the substance burning gives up its phlogiston to, and then combines with, the oxygen of the air', then the phlogiston theory would never have fallen into disrepute", because reduction and oxidation involve the gain or loss of an almost imponderable substance called electrons. However, such a hypothesis at that time would have been only one among the uncontrollable proliferation of inconsistent and untestable phlogistic hypotheses. Lewis's view was nothing like the original concept of phlogiston, in that for example, carbon and inflammable air do not differ from other substances by being almost completely constituted by electrons, the diminution of air in calcination is not due to saturation with electrons, and nitrous acid plus electrons does not make nitrous air, while nitrous acid plus a different quantity of electrons does not make phlogisticated air. Lewis's view was also not like the original concept of phlogiston in that his "phlogiston" was retained in calcination and combustion and so could not form the light and heat of combustion. In any case, electrons are not a substance in anything like the sense in which Stahl's principles were supposed to be solid substances. Had a concept akin to Lewis's been formulated at the time, it would been only one of the many late phlogistic hypotheses which could not form the bases for viable theories at that time, or would have been subject to the objection that it involved a gratuitous entity which was unnecessary in a theory, because the absorption or emission of pure air explained what was happening, as Pyle (2000) pointed out. It is more accurate to say that one set of functions of the phlogiston theories has had an echo in a generally radically different set of concepts in modern chemistry.

There have been differences concerning the impact of the unisolatability and unobservability of phlogiston. For example, Chang (2012, p. 7) argued that "the complaint that it was not possible to isolate phlogiston in its pure form has no force", and "it also won't do to say that phlogiston was an illegitimate scientific concept because it was

49 The arguments of Allchin (1992) mainly apply to late phlogistic theories dating from after 1791, and will not be examined in the present paper. 
unobservable.... And it is not clear that phlogiston was unobservable; to the phlogistonists, phlogiston was not only observable (in the flame that comes out of combustion, for example), but even directly manipulable (when it was transferred from one substance to another)". However, once it was clear that pure air was transferred in reactions in which phlogiston was supposed to be transferred, there was no longer evidence from transference for the existence of phlogiston, and Cavendish's (1784a) theories show that oxygen and phlogiston-as-negative-oxygen were incompatible as members of a single theory. Moreover, in Cavendish's, Kirwan's and Priestley's late phlogistic views in which phlogiston was present both in the combustible and the combusted, it was no longer clear that phlogiston could be present in the flame of combustion. Also, when a phlogistic theory was dealing with at least one unobservable and unisolatable principle or with observable substances that were not observable as constituents of substances of which they were supposed to be constituents, the new chemistry was almost entirely dealing with observable substances which were at observable temperatures, and this relative difference was crucial.

Chang (2012, pp. xix-xx) has argued phlogiston was killed prematurely, and that "judgement comes with a demand for action: if I think... that phlogistic chemistry was killed off prematurely, what am I going to do about it? If there is lost potential there, it should be recovered and developed. This is pluralism in practice-not the armchair pluralism of declaring 'Let a hundred flowers bloom', but an active pluralism of actually cultivating the 99 neglected flowers". So far however, he has not cultivated the multifarious phlogistic "flowers" that actually existed and were not taken further at the time. On the other hand, he (2012, p. 13) argues that the "truly pluralistic challenge would be to find and develop a science based on water as an element, with phlogiston". In connection with this he (2012, p. 13) firstly argues that "'water is an element' is only as wrong as 'oxygen is an element'", on the grounds that both have sub-atomic constituents, and that chemical reactions routinely involve ions. "What really hinges on calling it an element or a compound in an absolute sense?" (Chang 2012, p. 209). However, if sub-atomic constituents are taken into account when classifying chemical substances, and how to distinguish between substances is investigated, then as Hendry (2006, p. 867, 2012, p. 60) notes, "nuclear charge emerges as the only serious candidate", in which case the fundamental difference between chemical elements and compounds is the fundamental difference between substances involving constituents of only one atomic number and substances involving constituents of differing atomic numbers. Additional points are that Chang's argument jettisons the separate nature of chemistry and its useful distinctions, including that an element "is the final stage of chemical decomposition" (Scerri 2012, p. 70), and that "the actual presence of an element is what explains (at least partially) the chemical and physical features of its compounds" (Hendry 2012, p. 60). Alternatively, if the stance is taken that whatever it is that differentiates kinds in chemistry it is not microstructural essence (Needham 2002, p. 208), and that chemistry is essentially a macroscopic science of substances and their transformation (van Brakel 2000), then the crucial point is that "elements are just those that have no other chemical substances as components" (Hendry 2006, p. 864).

Chang (2012) argues that the conception of phlogiston as electrons justifies Cavendish's view that inflammable air $=$ water + phlogiston, as follows. In the electrolysis of water, the reaction at the negative electrode is $4 \mathrm{H}_{2} \mathrm{O}+4 \mathrm{e}^{-} \rightarrow 2 \mathrm{H}_{2}+4 \mathrm{OH}^{-}$; Chang (2012, p. 210) argues that "the production of hydrogen gas can be seen as a result of the combination of water and electrons, with the $\mathrm{OH}^{-}$ions as a by-product". The $4 \mathrm{OH}^{-}$which Chang argues that he can ignore as a "by-product" is over $90 \%$ of the result by weight. Chang (2012, p. 210) claims that the " $\mathrm{OH}^{-}$ions as a by-product" part of his story is not "a great big cheat". 
Chang's "imaginative" argument involves what would usually be counted as several philosophical and scientific errors concerning what is equivalence. It also departs radically from his proposed philosophical views and normative recommendations. He recommends the operational development (2012, p. 153) of testable hypotheses, but phlogiston was not an operational concept, phlogistic hypotheses were generally not testable, and when they were testable and experiments were fully investigated and the results were fully stated and properly taken into account, the tests were not successful. His argument started with the aim of developing a science with water as an element, but in order to develop the argument even as far as he has, he has had to abandon the requirement that water is an element in the sense that "element" is understood in chemistry. He recommends the development of many "systems of practice" (2012, p. 15) "which would be as incommensurable as possible (2012, p. 217-8) with other chemical systems" and result "in multiple conserved incommensurable systems of practice (2012, p. 224)." However, in this case he has not operationally developed a "system of practice". His view is incommensurable with later chemistry, but instead of going on developing it as a separate incommensurable theory, he ignores what he claims is a "by-product" in order to argue that the view is not inconsistent with later chemistry.

Much of the secondary literature has accurately recognised that phlogiston did not die in 1785 (e.g. Partington 1962, p. 605; White 1932, p. 182), but that at this stage there was an unprecedented production of more phlogistic systems. De la Métherie's, Crell's and Gren's journals continued to welcome phlogistic papers. Chang (2012, p. 48) argues that "there is little evidence of... harmful confusion caused by the co-existence of phlogiston and oxygen, and there isn't any convincing reason to think that the situation would have got much worse later if phlogiston had been kept", but he (2012, p. 162) notes a later situation of "a bewildering confusion of competing systems, almost one for each important chemist". The present paper shows, and the second paper will show further, that the proliferation of the late phlogistic systems was actually of at least one for each of the main participants, that this occurred largely because each such system had sufficient internal problems that it proved to be unacceptable in detail even to other phlogistians, that the result was a bewildering confusion, and that either phlogiston was in competition with oxygen for a place in a chemical theory, or the transference of oxygen during combustion and calcination removed the previous empirical evidence which had been held to be the empirical support for the existence of phlogiston.

Chang (2012, p. 291) argues that "We have to make a genuine effort to create and cultivate a set of systems, and observe how they develop, each of them in itself and also through mutual interaction. We have to keep this going long enough to see whether any tends in successfulness that we detect are stable". Yet sections "Phlogiston and related problems before 1766"-"Phlogistic theories and their problems, 1781-1791" of the present paper have shown how the late phlogistic theories developed, in themselves and through mutual interactions, over a quarter of a century, and have shown that there was a stable trend in which they became less successful, and eventually reached impasses as more experimental evidence accumulated, or included features which made them unacceptable even to other phlogistians.

Open Access This article is distributed under the terms of the Creative Commons Attribution 4.0 International License (http://creativecommons.org/licenses/by/4.0/), which permits unrestricted use, distribution, and reproduction in any medium, provided you give appropriate credit to the original author(s) and the source, provide a link to the Creative Commons license, and indicate if changes were made. 


\section{References}

Abbri, F.: Le terre, l'acqua, le arie: La rivoluzione chimica del Settecento. Bologna (1984)

Allchin, D.: Phlogiston after oxygen. Ambix 39, 110-116 (1992)

Beccaria, G.: Treatise on Artificial Electricity. Nourse, London (1776)

Beretta, M.: Bibliotheca Lavoisieriana. The Catalogue of the Library of Antoine-Laurent Lavoisier. Olschki, Florence (1995)

Bergman, T.: Physical and Chemical Essays. Trans. E Cullen, London: Murray (1784)

Bergman, T.: Dissertation on Elective Attractions. Murray, London (1785)

Berthollet, C.-L.: Considérations sur les Expériences de M. Priestley. Ann. de Chimie 3, 63-114 (1789)

Black, J.: Lectures on the Elements of Chemistry, 2 vols. ed. Robison, J. Edinburgh: Mundell (1803)

Boantza, V., Gal, O.: The 'absolute existence' of phlogiston: the losing party's point of view. Br. J. Hist. Sci. 44, 317-342 (2011)

Boyle, R.: On the difficulty of preserving flame without air. (1672) In: The Works of the Honourable Robert Boyle, in six volumes, new edn., vol. 3, 567-579. London (1772)

Boyle, R.: On the producibleness of chemical principles. (1680) In: The Works of the Honourable Robert Boyle, in six volumes, new edn., vol. 1, 587-661. London (1772)

Brisson, M.-J., Cadet de Gassicourt, L.-C.: Mémoire sur l'action du Fluide Électrique sur les Chaux Métalliques. (1775) In: Histoire de l'Académie Royale. Paris (1778)

Browning, P.: Benjamin Silliman and the beginnings of Chemistry at Yale. J. Chem. Educ. 11, 170-174 (1934)

Cavallo, T.: A Complete Treatise on Electricity. London (1777)

Cavallo, T.: A Complete Treatise on Electricity, 3rd edn. London (1786)

Cavendish, H.: Three papers, containing experiments on factitious air. Philos. Trans. R. Soc. Lond. 56, 141-184 (1766)

Cavendish, H.: Experiments on air. Philos. Trans. R. Soc. Lond. 74, 119-153 (1784a)

Cavendish, H.: Answer to Mr. Kirwan's remarks upon the experiments on air. Philos. Trans. R. Soc. Lond. 74, 170-177 (1784b)

Cavendish, H.: Experiments on air. Philos. Trans. R. Soc. Lond. 75, 372-384 (1785)

Cavendish, H.: The Scientific Papers of the Honourable Henry Cavendish, F.R.S., vol. II, ed. Thorpe, E. Cambridge: University Press (1921)

Chang, H.: We have never been Whiggish (About Phlogiston). Centaurus 51, 239-264 (2009)

Chang, $\mathrm{H}$.: Is water $\mathrm{H}_{2} \mathrm{O}$ ?. Springer, Dordrecht (2012)

Chardenon, J.P.: Dissertation sur l'exposition critique de la cause de l'augmentation du poids des matières métalliques après la calcination. Mercure de France, 28, 116-134 (1765)

Chardenon, J.P.: Lettre de M. Chardenon... en réponse à celle de M. Rihapotme... sur l'augmentation de poids des matières calcinées. Journal des Sçavans, 648-658 (1768)

Chardenon, J.P.: Mémoire sur l'augmentation de poids des métaux calcinés. Mém. de l'Acad. de Dijon 1, 303 (1769)

Crum Brown, A.: Note on the phlogistic theory. Proc. R. Soc. Edinb. 5, 328-330 (1866)

De Clave, E.: Nouvelle Lumière Philosophique. Varennes, Paris (1641)

De la Fond, J.: Précis historique et experimental des phénomenés électriques. Paris (1781)

De Milly, N.C. de Thy, Comte.: Mémoire sur la reduction des chaux metalliques, par le feu électrique. Obseratoins sur la Physique, 4, (1774)

Dumas, J.: Leçons sur la Philosophie Chimique. Paris; Ébrard (1836). Page ref. To 2nd edn., Paris: GauthierVillars (1878)

Fontana, F.: Opuscules physiques et chymiques. Trans. M. Gibelin. Paris: Nyon (1784)

Fourcroy, A-F.: Chimie. In Encyclopédie Méthodique, Tome Troisième, 262-781. Paris, Agasse (1796)

Glaser, C.: The compleat Chymist, or a new treatise of chymistry, 4th edn. John Starkey, London (1677)

Gren, F.: Grundriss der Naturlehre zum Gebrauch akademische Vorlesungen entworfen. Halle (1788)

Gren, F.: Grundriss der Naturlehre in seinem mathematischen und chemischen Theile neu arbeitet. Halle (1793)

Grison, E., Goupil, M., Bret, P. (eds.): A Scientific Correspondence during the Chemical Revolution: LouisBernard Guyton de Morveau and Richard Kirwan, 1782-1802. Berkeley: Office for History of Science and Technology (1994)

Guyton de Morveau, L-B.: Digressions académiques, ou Essais sur quelques sujets de Physique, de Chymie et d'Histoire naturelle. Dijon: Frantin (1772)

Guyton de Morveau, L-B., Maret, H., Durande, J.B.: Élémens de chymie, théorique et pratique. Dijon: Frantin (1777-1778)

Hendry, R.: Elements, compounds and other chemical kinds. Philos. Sci. 73, 864-875 (2006) 
Hendry, R.: Chemical substances and the limits of pluralism. Found. Chem. 14, 55-68 (2012)

Henly, W.: Experiments and observations in electricity. Philos. Trans. R. Soc. 67, 85-143 (1777)

Holmes, F.: The boundaries of Lavoisier's chemical revolution. Revue d'Histoire des Sci. 48, 9-48 (1995)

Holmes, F.: The revolution in chemistry and physics: overthrow of a reigning paradigm or competition between contemporary research programmes? Isis 91, 735-753 (2000)

Homberg, W.: Essays de Chimie. Article Premier: Des Principes de la Chimie en general". Histoire de l'Académie Royale des Sciences, avec Mémoires, 33-52 (1702)

Homberg, W.: Suite de Essays de Chimie. Article Troisième. Du Souphre Principe". Histoire de l'Académie Royale des Sciences, avec Mémoires, 88-96 (1705)

Juncker, J.: Conspectus Chemiae theoretico-practicae in forma Tabvlarvm repraesantatvs... e Dogmatibvs Becheri et Stahlii potissimvm explicantvr..., 2nd ed., trans. Demachy as Élémens de Chymie suivant les Principes de Becker et de Stahl. Paris: Hardy (1757). References are to vol 1 unless otherwise indicated

Jungnickel, C., McCormmach, R.: Cavendish: The Experimental Life. Bucknell, Lewisburg (1999)

Kirwan, R.: Continuation of the experiments and observations on the specific gravities and attractive powers of various saline substances. Philos. Trans. R. Soc. Lond. 72: 179-xxxv (1782)

Kirwan, R.: Remarks on Mr. Cavendish's experiments on air. Philos. Trans. R. Soc. Lond. 74, 154-169 (1784a)

Kirwan, R.: Reply to Mr. Cavendish's Answer. Philos. Trans. R. Soc. Lond. 74, 178-180 (1784b)

Kirwan, R.: An essay on phlogiston and the constitution of acids. Johnson, London (1789)

Kitcher, P.: The Advancement of Science. Oxford University Press, Oxford (1993)

Klein, U., Lefèvre, W.: Materials in Eighteenth-Century Science. MIT Press, Cambridge, MA (2007)

Kopp, H.: Geschichte der Chemie, vol. 1. Vieweg, Braunschweig (1843)

Kopp, H.: Geschichte der Chemie, vol. 3. Vieweg, Braunschweig (1845)

Kusch, M.: Scientific pluralism and the chemical revolution. Stud. Hist. Philos. Sci. 49, 69-79 (2015)

Lavoisier, A-L.: Opuscules Physiques et Chymiques. Paris (1774). Page refs to Oeuvres de Lavoisier, vol 1. Paris, Imprimerie Imperiale (1864)

Lavoisier, A-L.” Mémoire sur la nature du principe qui se combine avec les métaux pendant leur calcination et qui augmente le poids (1775/8) in Oeuvres de Lavoisier, vol 2, 105-121. Paris: Imprimerie Imperiale (1862)

Lavoisier, A-L.: Mémoire sur l'existence de l'air dans l'acide nitreux, et sur les moyens de décomposer et de recomposer cet acide. (1776) in Oeuvres de Lavoisier, vol 2, 129-138. Paris: Imprimerie Imperiale (1862)

Lavoisier, A-L.: Mémoire sur la combustion du phosphore de Kunckel, et de la formation de son acide. In: Oeuvres de Lavoisier, vol 2, 139-152. Paris: Imprimerie Imperiale (1862) (1777a)

Lavoisier, A-L.: Mémoire sur la combustion en général. In: Oeuvres de Lavoisier, vol. 2, 212-224. Paris: Imprimerie Imperiale (1862) (1777b)

Lavoisier, A-L.: Mémoire sur la dissolution de mercure dans l'acide vitriolique, et sur la résolution de cet acide en acide sulfureux aériforme et en air éminement respirable. In Oeuvres de Lavoisier, vol 2, 194-198. Paris: Imprimerie Imperiale (1862) (1777c)

Lavoisier, A.-L.: Réflexions sur la calcination et la combustion, à l'occasion d'un ouvrage intituled: Traité chimique de l'air et du feu. In: Oeuvres de Lavoisier, vol. 2, 391-402. Paris: Imprimerie Imperiale (1862) (1782)

Lavoisier, A.-L.: Mémoire dans laquelle on a pour objet de prouver que l'eau n'est point une substance simple, un élément proprement dit, mais qu'elle est susceptible de décomposition et de recomposition. In: Oeuvres de Lavoisier, vol 2, 334-359. Paris: Imprimerie Imperiale (1862) (1783)

Lavoisier, A.-L.: Oeuvres de Lavoisier, Correspondance volume VI. In: Bret, P. (ed). Paris: Académie des Sciences (1997) (1789-91)

Lefebvre (Le Fèvre), N.: A Compleat body of Chymistry. 2 vols. London: Ratcliffe (1664)

Lemery, N.: A course of chymistry, 1st edn. Kettilby, London (1677)

Lemery, N.: A course of chymistry, 4th edn. trans. from 11th French edn. London: Bell, Midwinter, Taylor and Osborn (1720)

Leonhardi, J.: Macquer's Chymisches Wörterbuch, 7 vols. Leipzig (1790)

Lewis, G.N.: The Anatomy of Science. Yale University Press, New Haven (1926)

Macquer, P.: Elements of the Theory and Practice of Chymistry, 2nd edn. Donaldson, Edinburgh (1764)

Macquer, P.: Dictionnaire de Chymie. Paris: Lacombe (1766)

Macquer, P.: Dictionnaire de Chymie, 2nd edn. Barrois, Paris (1778)

Mayow, J.: Tractatus Duo. Sheldonian, Oxford (1668)

Mayow, J.: Tractatus Quinque Medico-Physici. Sheldonian, Oxford (1674) 
McEvoy, J.: Joseph Priestley, 'Aerial Philosopher': Metaphysics and Methodology in Priestley's Chemical Thought from 1772-1781. Parts 1-3, Ambix 25, 1-55; 93-116, and 153-175; Part 4: Ambix 26, 16-38 (1978-9)

McEvoy, J.: Enlightenment and dissent in science: Joseph Priestley and the limits of theoretical reasoning. Enlight. Dissent 2, 47-68 (1983)

McEvoy, J.: Causes and Laws, Powers and Principles: The Metaphysical Foundations of Priestley's Concept of Phlogiston. In Science, medicine and Dissent: Joseph Priestley (73--1804). Edited by R Anderson and C. Lawrence. London: Wellcome Trust/Science Museum (1987)

McEvoy, J.: Continuity and discontinuity in the chemical revolution. Osiris 4, 195-211 (1988)

McEvoy, J.: Joseph Priestley and the chemical revolution: a thematic overview. In: Schwarz, A., McEvoy, J. (eds.) Motion Towards Perfection: The Achievement of Joseph Priestley. Skinner House, Boston (1990)

McEvoy, J.: Positivism, Whiggism and the Chemical Revolution. Hist. Sci. 35, 1-32 (1997)

Meyer, E.: A History of Chemistry. Trans. G. McGowan. London: Macmillan (1891)

Murray, J.: A System of Chemistry, 4 vols, 4th edn. Francis Pillans, Edinburgh (1819)

Musgrave, A.: Why did oxygen supplant phlogiston? Research programmes in the chemical revolution. In: Howson, C. (ed.) Method and Appraisal in the Physical Sciences, pp. 181-210. Cambridge University Press, Cambridge (1976)

Needham, P.: The discovery that water is $\mathrm{H}_{2} \mathrm{O}$. Int. Stud. Philos. Sci. 16, 205-226 (2002)

Needham, P.: Questioning the justification of past science. Int. Stud. Philos. Sci. 27, 85-93 (2013)

Odling, W.: On the revived theory of phlogiston. Proc. R. Inst. G B 6, 315-325 (1871)

Partington, J.: A History of Chemistry, vol. 2. Macmillan, London (1961)

Partington, J.: A History of Chemistry, vol. 3. Macmillan, London (1962)

Partington, J.R., McKie, D.,: Historical studies in the phlogiston theory - parts I-IV. Ann. Sci. 2, 361-405; 3, 1-59 and 337-372; 4, 113-149 (1937-9)

Priestley, J.: The History and Present State of Electricity with original Experiments, 2nd edn. Dodsley, Johnson, Davenport and Cadell, London (1769)

Priestley, J.: Experiments and Observations on Charcoal. Philos. Trans. R. Soc. 60, 211-227 (1770)

Priestley, J.: Observations on different kinds of air. Philos. Trans. R. Soc. 62, 147-265 (1772)

Priestley, J.: Experiments and Observations on Different Kinds of Air. Johnson, London (1774)

Priestley, J.: Experiments and Observations on Different Kinds of Air, vol. II. Johnson, London (1775a)

Priestley, J.: An account of further discoveries in Air; in letters to Sir John Pringle, Bart. P.R.S. and the Rev. Dr. Price, F.R.S. Philos. Trans. R. Soc. 65, 384-394 (1775b)

Priestley, J.: Experiments and Observations on Different Kinds of Air, vol. III. Johnson, London (1777)

Priestley, J.: Experiments and observations relating to various branches of natural philosophy, with a continuation of the observations on air, vols. I, II, and III. London: Johnson $(1779,1786)$

Priestley, J.: Experiments relating to phlogiston and the seeming conversion of water into air. Philos. Trans. R. Soc. 73, 398-434 (1783)

Priestley, J.: Experiments and observations relating to the principle of acidity, the composition of water and phlogiston. Philos. Trans. R. Soc. 78, 147-157 (1788a)

Priestley, J.: Additional experiments and observations relating to the principle of acidity, the composition of water and phlogiston. Philos. Trans. R. Soc. 78, 313-330 (1788b)

Priestley, J.: Objections to the experiments and Observations relating to the principle of acidity, the composition of water and phlogiston. Philos. Trans. R. Soc. 79, 7-20 (1789)

Priestley, J.: Experiments and Observations on Different Kinds of Air, and Other Branches of Natural Philosophy, Connected to the Subject: Being the Former Six Volumes Abridged and Methodized, with Many Additions, vols. I, II, and III. London: Johnson (1790a, b and c)

Priestley, J.: Farther Experiments relating to the Decomposition of dephlogisticated and inflammable air. Philos. Trans. R. Soc. 81, 213-222 (1791)

Priestley, J.: Experiments on the Generation of Air from Water. Johnson, London (1793)

Priestley, J.: Heads of Lectures on a Course of Experimental Philosophy Particularly Including Chemistry, Delivered at the New College in Hackney. Johnson, London (1794)

Priestley, J.: The doctrine of phlogiston established and that of the composition of water refuted. Northumberland (1800)

Priestley, J.: Scientific Correspondence of Joseph Priestley. Ed. Bolton, H. New York (1892)

Pyle, A.: The rationality of the chemical revolution. In: Nola, R., And Sankey, H. After Popper, Kuhn and Feyerabend: Recent Issues in Theories of Scientific Method, pp. 99-124. Dordrecht: Kluwer (2000)

Rappaport, R.: Rouelle and Stahl: the phlogistic revolution in France. Chymia 7, 73-102 (1961)

Rey, J.: Essays de Jean Rey laquelle l'Estain et le Plomb augmentent de poids quant on les calcine. Millanges, Bazas (2000) 
'Ribapotme, Prètre': Lettre sur l'augmentation de poids dans la calcination, adressé a Mss les Auteurs du Journal des Sçavans, pp. 130-147 (1768)

Rodwell, G.: On the theory of phlogiston. Philos. Mag. J. Sci. 35, 1-32 (1868)

Sage, B.-G.: Élémens de Minéralogie Docimastique. Lormel, Paris (1772)

Saussure, T.: Observations on the combustion of several sorts of charcoal, and on hydrogen gas. (Nicholson's) J. Nat. Philos. Chem. Arts 26: 161-176 and 300-309 (1810)

Scerri, E.: What is an element? What is the periodic table? And what does quantum mechanics contribute to the question? Found. Chem. 14, 69-81 (2012)

Scheele, C.: The Collected Papers of Carl Wilhelm Scheele. Bell, London (1931)

Schofield, R.: The Scientific Background of Joseph Priestley. Ann. Sci. 13, 148-163 (1957)

Schofield, R.: Joseph Priestley, the theory of oxidation and the nature of matter. J. Hist. Ideas 25, 285-294 (1964)

Schofield, R.: A Scientific Autobiography of Joseph Priestley. MIT Press, Cambridge (1966)

Schofield, R.: The enlightened Joseph Priestley. The Pennsylvania State University Press (2004)

Scopoli, G.: Gedanken über das Phlogiston. Beyträge zu den chemischen Annalen 1(4), 3-9 (1786)

Séguin, A.: Suite du Mémoire sur la Combustion du Gaz Hydrogène dans des Vaisseaux clos. Ann. de Chimie 9, 30-50 (1791)

Sennert, D.: De Chymicorum Cum Aristotelicis et Galenicis Consensu ac Dissensu, Liber I. Wittenberg (1619)

Siegfried, R.: Lavoisier and the phlogistic connection. Ambix 36, 31-40 (1989)

Stahl, G.: Zymotechnia fundamentalis, seu Fermentationis theoria generalis. Halle (1697)

Stahl, G.: Zufällige gedanken und nützliche bedencken über der Streit von dem so gennanten Sulphure. Halle (1718)

Stahl, G.: Ausführliche Betrachtung und zulängliche Beweiss von den Saltzen, dass dieselbe aus einer Zarten Erde, mit Wasser innig verbunden bestehen. Halle (1723)

Stahl, G.: Fundamenta Chymiae Dogmaticae and Experminentalis. Trans P. Shaw as Philosophical Principles of Universal Chemistry. Osborn and Longman, London (1730)

Stahl, G.: Traité du Soufre. Trans. d'Holbach. Paris, Didot (1766)

Stewart, J.: The reality of phlogiston in Great Britain. Hyle 18, 175-194 (2012)

Sudduth, W.: Eighteenth-century identifications of electricity with phlogiston. Ambix 25, 131-147 (1978)

Thomson, T.: History of Chemistry. Colburn and Bentley, London (1830)

Van Brakel, J.: Philosophy of Chemistry. Leuven University Press, Leuven (2000)

Van Marum, M.: Martinus van Marum: Life and Work, vol. 5. Noordhoff, Leyden (1974)

Verbruggen, F.: How to explain priestley's defense of phlogiston. Janus 54, 47-89 (1972)

Watson, R.: Chemical Essays. Merrill, Cambridge (1781)

Watts, H.: Dictionary of Chemistry. Longmans, Green, London (1872)

Weber, J.: Neuentdeckte Natur und Eigenschaften des Kalkes und der Azenden Korper. Weber, Berlin (1778) 